\title{
Fish oil diet associated with acute reperfusion related hemorrhage, and with reduced stroke-related sickness behaviors and motor impairment
}

\section{Michaela C. Pascoe ${ }^{1}$ *, David W. Howells ${ }^{2}$, David P. Crewther ${ }^{1}$, Nicki Constantinou ${ }^{3}$, Leeanne M. Carey ${ }^{2}$, Sarah S. Rewell ${ }^{2}$, Giovanni M. Turchini ${ }^{4}$, Gunveen Kaur ${ }^{5}$ and Sheila G. Crewther ${ }^{6}$}

${ }^{1}$ Brain Sciences Institute, Swinburne University, Melbourne, VIC, Australia

2 Florey Neuroscience Institutes, Melbourne, VIC, Australia

${ }^{3}$ School of Psychology, Deakin University, Geelong, VIC, Australia

${ }^{4}$ School of Life and Environmental Sciences, Deakin University, Warrnambool, VIC, Australia

${ }^{5}$ Institute of Sport Exercise and Active Living, Victoria University, Melbourne, VIC, Australia

${ }^{6}$ School of Psychological Science, La Trobe University, Melbourne, VIC, Australia

Edited by:

Ashfaq Shuaib, University of Alberta, Canada

Reviewed by:

Mustafa Alam, University of Alberta, Canada

lan Winship, University of Alberta,

Canada

\section{*Correspondence:}

Michaela C. Pascoe, Department of

Clinical Neuroscience and

Rehabilitation, Institute of

Neuroscience and Physiology,

Sahlgrenska Academy, University of

Gothenburg, Box 440, Gothenburg

SE-405 30, Sweden

e-mail: michaela.pascoe@neuro.gu.se
Ischemic stroke is associated with motor impairment and increased incidence of affective disorders such as anxiety/clinical depression. In non-stroke populations, successful management of such disorders and symptoms has been reported following diet supplementation with long chain omega-3-polyunsaturated-fatty-acids (PUFAs). However, the potential protective effects of PUFA supplementation on affective behaviors after experimentally induced stroke and sham surgery have not been examined previously. This study investigated the behavioral effects of PUFA supplementation over a 6-week period following either middle cerebral artery occlusion or sham surgery in the hooded-Wistar rat. The PUFA diet supplied during the acclimation period prior to surgery was found to be associated with an increased risk of acute hemorrhage following the reperfusion component of the surgery. In surviving animals, PUFA supplementation did not influence infarct size as determined 6 weeks after surgery, but did decrease omega-6-fatty-acid levels, moderate sickness behaviors, acute motor impairment, and longer-term locomotor hyperactivity and depression/anxiety-like behavior.

Keywords: polyunsaturated fatty acids, middle-cerebral-artery-occlusion, mood, stroke

\section{INTRODUCTION}

Ischemic stroke affects 15 million people a year and is a leading cause of disability worldwide (1). Recovery after stroke is associated with high incidences of behavioral and affective disorders including anxiety and $(2,3)$ clinical depression $(4)$, which are commonly co-morbid $(5,6)$. In non-stroke affected populations, depressive disorder is associated with delirium $(7,8)$. Delirium is also common following stroke (9). Anxiety, depression, and delirium all negatively influence recovery after stroke $(9,10)$. Depressive disorder is also similarly closely linked to inflammation related "sickness behaviors" (11). Sickness behaviors are defined as the normal, ubiquitous responses to infection seen in all animal species examined and bear close biological resemblance to clinical depression (11). Sickness behaviors usually suppress normal activities such as eating and drinking. Thus to achieve the best prognostic outcome for stroke survivors, it is important to design better management regimes for post-stroke affective disorders (4) and sickness behaviors in general.

An alternative therapy for the generic treatment of depression (12), anxiety (13), and hyperactive symptoms (14) are long chain omega-3 polyunsaturated fatty acids ( $n$-3-LC-PUFA) and in particular eicosapentaenoic acid (EPA; 20:5n-3) and docosahexaenoic acid (DHA; 22:6n-3) (14). Many studies, however, regarding the effectiveness of $n$-3-LC-PUFA in the treatment of emotional and behavioral disorders have found inconsistent results, and the number of studies is limited, indicating a need for additional research (15). The influence of such $n$-3-LC-PUFA supplementation on mood and behavioral disorders has not previously been investigated after stroke either in humans or in animals after experimentally induced ischemia via middle cerebral artery occlusion (MCAo).

n-3-LC-PUFAs are highly bioactive compounds, commonly derived from dietary fish oil, and have anti-inflammatory effects at optimal doses (12). $n$-3-LC-PUFAs have anti-thrombotic effects (16) and contribute to reduced platelet coagulation (17). Accordingly, some animal studies demonstrate that $n$-3-LC-PUFAs increase bleeding after experimentally induced intracerebral hemorrhage (18). We are unaware of any research indicating a potential risk of PUFA supplementation on bleeding after cerebral ischemia. Conversely, a number of previous studies have demonstrated neuroprotective effects of $n$-3-LC-PUFAs after cerebral ischemia in animal models (19-21). Thus, in the present study, we compared the effects of diet (n-3-LC-PUFA supplementation to the basal diet vs. basal diet) over the 6-weeks after surgery (either MCAo or sham surgery) in rats. In particular we aimed to study the effects of diet on surgically induced acute and longer-term motor and sickness behaviors, including behaviors commonly interpreted 
to reflect excessive anxiety or depressive-like behaviors in the rodent model.

We hypothesized that following MCAo surgery animals would show reduced food and water consumption, compared to shams. Additionally, we hypothesized that the $n$-3-LC-PUFA diet supplemented animals would show less reduction in food and water consumption, and body weight post-surgery, compared to the basal diet fed animals.

Acute inabilities to make co-ordinated motor movements have regularly been reported in rats post MCAo $(22,23)$ and decrease in response to neuroprotective agents (24-26). Thus, we hypothesized that the $n$-3-LC-PUFA supplemented animals would also show less acute MCAo related motor impairments on a battery of widely used neurological impairment tests $(22,23)$ compared to basal diet fed rats.

We hypothesized that hyperactive locomotor behaviors assessed using the free exploration test, would not correlate with anxietylike behavior in this test, defined by percentage of emergence time spent in the center of the open-field arena. Previous authors have speculated that MCAo related changes in locomotion might arise from an inability to habituate to unfamiliar environments, possibly related to spatial mapping difficulties induced by hippocampus cell death (27-30). Therefore, spatial mapping abilities were assessed here using the spatial displacement recognition test, which has previously been employed to study spatial memory deficits post-stroke in the rodent model (28, 31-33).

We hypothesized that MCAo operated animals would show more long-term stroke-related anxiety-like and hyperactive locomotor behaviors than sham operated animals (MCAo vs. Sham). Finally, we hypothesized that after surgery animals supplemented with $n$-3-LC-PUFA would show less long-term sickness or anxietylike and locomotor behaviors than basal diet fed animals (n-3-LCPUFA vs. Basal). Long-term was defined as occurring at 2, 4 , or 6 weeks following surgery.

In summary, we anticipated that $n$-3-LC-PUFA diet supplementation would reduce acute MCAo related motor impairments, and sickness behaviors. We expected the beneficial effects of $n$-3-LC-PUFA diet supplementation to persist longer term, as evidenced by a longer-term reduction in rodent behaviors, interpreted to reflect stroke-related behavioral and affective disorders.

\section{MATERIALS AND METHODS ANIMALS AND DESIGN}

The experiment used two surgery groups (MCAo and Sham groups) and two diet groups (basal and $n$-3-LC-PUFA supplementation) with repeated measures outcomes. Adult male hoodedWistar rats (Laboratory Animal Services, The University of Adelaide, Australia) commonly used in stroke research (34-36) were separately housed $\left(21 \pm 2^{\circ} \mathrm{C}, 12: 12 \mathrm{~h}\right.$ light-dark cycle). Food and water were available ad libitum and consumption and body weight were measured daily. Acclimatization to housing and diet condition began 1 week prior to surgery and continued until animal sacrifice (via isoflurane anesthesia; Cat No. AHN3640-250ML, Baxter, Old Toongabbie, NSW, Australia) at 6 weeks post-surgery. Animal behavior was studied until 6 weeks post-surgery as previous research, in non-stroke-related areas, has demonstrated that
6 weeks of oral supplementation with omega-3 is associated with anti-depressive-like behavioral effects in rodent models (37). In the week following surgery only, animals were provided with sunflower seeds and soft food (Sustagen ${ }^{\circledR}$ Everyday Nestlé, Notting Hill, VIC, Australia) additional to their respective diets, to encourage eating and weight gain. Surgeries and behavioral testing took place in the lights-on phase. The experimental protocol required 48 animals; however 11 rats in the $n$-3-LC-PUFA MCAo group died immediately following withdrawal of the suture thread. A further 16 rats ( $n$-3-LC-PUFA MCAo, $n=7$; Basal MCAo, $n=9$ ) were culled due to MCAo induced motor impairments and clinical symptoms deemed too large for the animal to survive. These animals were replaced and thus, the total number of animals used in the present study was $75(n=29 n$-3-LC-PUFA MCAo; $n=22$ Basal MCAo; $n=12 n$-3-LC-PUFA sham; $n=12$ Basal Sham).

\section{ETHICS STATEMENT}

Ethics approval was granted by the Austin Health Research Ethics Unit (10/3865) and was conducted in accordance with the Australian Code of Practice for the use of animals for scientific purposes (38).

\section{DIETARY REGIME}

Animals were randomly assigned to $n$-3-LC-PUFA diet condition \{Specialty Feeds, Cat No. SF09-109 5\% Fat High N3 Modified Rodent Diet, Glen Forest, WA, Australia [EPA 20:5 n-3 5\% of total free fatty acid (FFA), DHA 22:6 n-3 23.8\% of total fatty acids]\}, selected as it has previously been demonstrated to reduce oxidative stress in the rat model (39) or basal diet condition (Specialty Feeds, Cat No. AIN93G; Glen Forest, WA, Australia).

\section{RIGHT MIDDLE CEREBRAL ARTERY OCCLUSION}

Within each diet condition, animals were randomly assigned to MCAo or sham surgery condition. Surgeries were performed according to the protocol of Longa (40) and its modifications by Spratt (41). Briefly, anesthesia was induced (5\% in oxygen) and maintained ( $2 \%$ in oxygen) with Isoflurane via a nose cone. Vital signs were monitored using iWORX (Cat No. PO2-300D, iWORX, Dover, NH, USA). Body temperature was maintained at $37^{\circ} \mathrm{C}$. Atropine $(0.2 \mathrm{ml} 600 \mu \mathrm{g} / \mathrm{ml}$, Pfizer Australia Pty Ltd., NSW, Australia) was administered intraperitoneally to inhibit bronchial secretions and salivation. Cerebral blood flow was measured using laser doppler flowmetry (LDF). The scalp was thinned using a dental burr and the Laser Dopler was attached to a laboratorymade rubber probe holder attached to skull with instant adhesive (Loctite 406 instant adhesive, Cat No. 265606, Henkel, Sydney, NSW, Australia). An incision was made in the neck, small branching blood vessels were cauterized, the external carotid artery was ligated, an incision made in the right external carotid artery, a 0.4-mm diameter silicone tipped suture thread inserted into the incision, passed via the right external carotid and up the internal carotid artery. MCAo was $90 \mathrm{~min}$ during which incisions were closed (4.0 silk sutures, Cat No. 90352, Dynek Pty Ltd., Port Adelaide, SA, Australia) and animals were removed from anesthesia. For reperfusion, animals were re-anesthetized, incisions re-opened and the MCA-occluding suture retracted. Vital signs 
and during reperfusion were monitored using iWORX (Cat No. PO2-300D, iWORX, Dover, NH, USA). Animal breathing was also monitored. Animals that died during the surgical or after the reperfusion procedure, or within the first $24 \mathrm{~h}$ after surgery, were documented and post mortem autopsy was conducted to determine cause of death. Hemorrhage was determined at the time of autopsy, by the presence of blood pooled around the base of skull. Analgesia was provided as paracetamol (Cat No. 569925, Sanofi-Aventis, Macquarie Park, NSW, Australia) crushed and dissolved into drinking water $(0.15 \mathrm{mg} / \mathrm{ml}$ water $)$. Saline was injected (i.p.) daily for 3 days following surgery [ $3 \mathrm{ml}$ Sodium Chloride Solution (0.9\%), Cat No. 7647-14-5, Tocris Bioscience, Bristol, UK]. Sham animals underwent identical procedures with the exclusion of thread insertion into the MCA. Table 1 displays animal groups, final successful numbers, and behavior testing timetable.

\section{ACUTE STROKE-RELATED MOTOR IMPAIRMENT MEASURES}

Motor impairments were assessed daily in the first 5 days postsurgery using the forelimb flexion test [MCAo affected rats hold left forelimb between $45^{\circ}$ and $90^{\circ}$ when lifted from base of tail (22)] the torso twisting test [MCAo affected rats show curling of the head and forelimbs toward the paralytic side of the body, when held via tail (22)] the lateral push test [MCAo affected rats show weakened resistance when pushed toward the paralytic left side (22)] and the circling [animals with infarct damage circle toward the opposite side of the damage (22)] and motor ability, observations (walking, grooming, and rearing behaviors) which collectively measure the acute inability to make co-ordinated motor movements, regularly been reported and studied in rats post MCAo compared to sham surgery $(22,23)$. These motor impairments are less severe in animals exposed to neuroprotective agents (24-26), thus, we aimed to determine if acute motor disability was decreased after $n$-3-LC-PUFA supplementation.

\section{LONGER-TERM ISCHEMIA ASSOCIATED BEHAVIORAL AND AFFECTIVE DISORDERS}

The battery of behavioral tests designed to model ischemia-related affective behaviors were administered and recorded on video in the second, and then repeated in the fourth and sixth weeks poststroke. The same animals were tested at each time point. Behavior video was scored by an observer (NC) who was blind to animal diet and surgery condition. Animal behaviors were scored by a second observer (MP), and the inter-rater reliability correlation was statistically significant, $r^{2}=0.97$. To test for longer-term sickness behaviors and particularly depression and anxious like behaviors after surgery, we used the novel object exploration test and a modified open-field test that measures the conflict between a rat's mutual drives to both avoid and approach unfamiliar and potentially fear inducing stimuli/environments $(32,42-47)$. To asses the locomotor hyperactivity often reported from as early as 5 min to 5 weeks after MCAo surgery $(29,30,48,49)$ and in rodent models of anxiety and depression (50-54), we used a modified free exploration test, which eliminates the forced exploration and related stress normally associated with the commonly used open-field test $(55,56)$. All behavior was recorded using a digital camcorder (Canon Legria, HG20) and was stored as a MPEG-TS video file. All apparatus were cleaned with $70 \%$ ethanol between trials (Cat No. EA043-10L, Chem-Supply, Gillman, SA, Australia).

\section{FREE EXPLORATION TEST}

Animals were habituated $(15 \mathrm{~min})$ to a laboratory constructed black Plexiglass hide box $(30 \mathrm{~cm} \times 15 \mathrm{~cm} \times 19 \mathrm{~cm})$ the day prior and re-acclimated $(5 \mathrm{~min})$ immediately prior to testing. The open field was a transparent Plexiglass arena $\left(1 \mathrm{~m}^{2}\right)$ illuminated $(\sim 500$ lux $)$. The hide box was positioned inside one wall of the open field. Animals were scored for locomotor hyperactivity (number of times fully emerged from the hide box, i.e., emergence number) and time spent fully emerged from hide box and

Table 1 | Experimental timeline showing order and timing of treatment and testing.

\begin{tabular}{|c|c|c|c|c|}
\hline $\begin{array}{l}\text { Animal surgery } \\
\text { and diet group }\end{array}$ & $\begin{array}{l}\text { MCAo surgery and } \\
n-3-L C-P U F A \text { diet }\end{array}$ & $\begin{array}{l}\text { MCAo surgery and } \\
\text { basal diet }\end{array}$ & $\begin{array}{l}\text { Sham surgery and } \\
n-3-L C-P U F A \text { diet }\end{array}$ & $\begin{array}{l}\text { Sham surgery and } \\
\text { basal diet }\end{array}$ \\
\hline 1 week prior to & Diet/housing acclimation & Diet/housing acclimation & Diet/housing acclimation & Diet/housing acclimation \\
\hline surgery & Surgery & Surgery & Surgery & Surgery \\
\hline $\begin{array}{l}\text { Day } 1-5 \\
\text { post-surgery }\end{array}$ & $\begin{array}{l}\text { Acute motor impairment } \\
\text { testing }\end{array}$ & $\begin{array}{l}\text { Acute motor impairment } \\
\text { testing }\end{array}$ & $\begin{array}{l}\text { Acute motor impairment } \\
\text { testing }\end{array}$ & $\begin{array}{l}\text { Acute motor impairment } \\
\text { testing }\end{array}$ \\
\hline $\begin{array}{l}2 \text { weeks } \\
\text { post-surgery }\end{array}$ & $\begin{array}{l}\text { Free exploration, spatial } \\
\text { displacement recognition, and } \\
\text { novel object exploration testing }\end{array}$ & $\begin{array}{l}\text { Free exploration, spatial } \\
\text { displacement recognition, and } \\
\text { novel object exploration testing }\end{array}$ & $\begin{array}{l}\text { Free exploration, spatial } \\
\text { displacement recognition, and } \\
\text { novel object exploration testing }\end{array}$ & $\begin{array}{l}\text { Free exploration, spatial } \\
\text { displacement recognition, and } \\
\text { novel object exploration testing }\end{array}$ \\
\hline $\begin{array}{l}2 \text { weeks } \\
\text { post-surgery }\end{array}$ & $\begin{array}{l}\text { Behavioral testing as specified } \\
\text { in week } 2 \text { post-surgery }\end{array}$ & $\begin{array}{l}\text { Behavioral testing as specified } \\
\text { in week } 2 \text { post-surgery }\end{array}$ & $\begin{array}{l}\text { Behavioral testing as specified } \\
\text { in week } 2 \text { post-surgery }\end{array}$ & $\begin{array}{l}\text { Behavioral testing as specified } \\
\text { in week } 2 \text { post-surgery }\end{array}$ \\
\hline $\begin{array}{l}6 \text { weeks } \\
\text { post-surgery }\end{array}$ & $\begin{array}{l}\text { Behavioral testing as specified } \\
\text { in week } 2 \text { post-surgery }\end{array}$ & $\begin{array}{l}\text { Behavioral testing as specified } \\
\text { in week } 2 \text { post-surgery }\end{array}$ & $\begin{array}{l}\text { Behavioral testing as specified } \\
\text { in week } 2 \text { post-surgery }\end{array}$ & $\begin{array}{l}\text { Behavioral testing as specified } \\
\text { in week } 2 \text { post-surgery }\end{array}$ \\
\hline & Sacrifice & Sacrifice & Sacrifice & Sacrifice \\
\hline
\end{tabular}

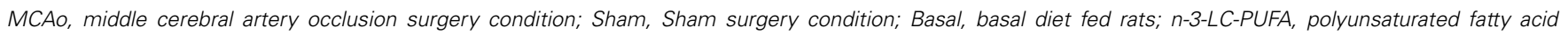
supplemented rats. 
moving around the arena (emergence duration) for 4 min. Given that the MCAo procedure and the associated neurodegenerative damage result in increased locomotor, activity per se (29, 30, 48, 49) we suggest that the above-mentioned measures may not reflect anxiety-like behaviors in MCAo operated animals, but instead may only be another measure of locomotion hyperactivity. Animals were however also scored for anxiety-like behavior that was defined as the avoidance of the center and quantified as the percentage of time spent in the center area also.

\section{SPATIAL DISPLACEMENT RECOGNITION}

Animals were acclimated $(5 \mathrm{~min})$ to the testing box $(40 \mathrm{~cm} \times$ $40 \mathrm{~cm} \times 60 \mathrm{~cm})$ the day prior to testing. On the day of testing, animals were placed in the testing box, positioned with their nose facing the mid-point of the wall opposite the objects, to prevent an unintentional bias of placing the animal in an orientation favoring a particular object (57). Object contact was defined as when the mouth, nose, and/or paw touched the object or when the nose of the rat was within $1 \mathrm{~cm}$ surrounding the object. Contact judged as accidental, such as bumping the object as the animal passed or grooming behavior was not counted. The number of object contacts and the duration of these were recorded.

The spatial displacement recognition testing consisted of two habituation trials ( 3 min each) to two identical objects. Habituation trials were separated by a 2-min interval, during which the animal was returned to the home cage. The location of one of the two objects was then moved and the animal was placed in the testing box for a single 3 min recognition trial.

\section{NOVEL OBJECT EXPLORATION}

The novel object exploration trial took place immediately after the spatial displacement recognition trial, separated only by a 2 -min interval (animal returned to home cage). Testing took place in the same box used for the spatial displacement recognition test. Rats were placed in the testing box for a single 3-min trial. The familiar object was placed in one corner of the box and the novel object was placed in the opposite corner. Object placement and selection were counterbalanced across trials and animals. Contact definition is consistent with that described above for the spatial displacement recognition test.

\section{TISSUE COLLECTION}

Tissue was collected using two methods: (a) whole brain for total FFA analysis ( $n=5 n$-3-LC-PUFA MCAo; $n=6$ Basal MCAo; $n=6 n$-3-LC-PUFA Sham; $n=6$ Basal Sham) animals were anesthetized via Isoflurane overdose, decapitated via guillotine, brains removed, snap frozen in liquid nitrogen (Liquid Nitrogen Services Pty Ltd., Melbourne, VIC, Australia), and stored at $-80^{\circ}$. (b) Perfusion for infarct analysis $(n=6 n$-3-LC-PUFA MCAo; $n=6$ Basal MCAo; $n=6 n$-3-LC-PUFA Sham; $n=6$ Basal Sham). Once anesthetized, the rib cage and diaphragm were cut, a perfusion needle placed into the left ventricle of the heart and the right atrium cut. Saline $(90 \mathrm{ml})(1.8 \%)$ was infused $(5 \mathrm{~min})$, followed by paraformaldehyde (PFA) (4\%) (270 ml) (15 min), using a perfusion pump (Peri-Star Pro 4-channel, high rate pump, Cat No. PERIPRO-4HS, World Precision Instruments, Hilton, SA, Australia) $(18 \mathrm{ml} / \mathrm{min})$. Brains were removed and placed directly into
PFA (4\%) for $24 \mathrm{~h}$, before being changed to $30 \%$ sucrose, where they remained until the time of paraffin embedding.

\section{FATTY ACID ANALYSIS}

To confirm that the $n$-3-LC-PUFA supplementation resulted in changes in brain phospholipids levels of fatty acids, whole brain frozen tissue was ground up, and tissue lipids extracted by dichloromethane/methanol (2:1) overnight, as described by Sinclair et al. (58). Samples were filtered, saline added $(1 \mathrm{ml}$ of $0.9 \%)$, and vortexed $(1 \mathrm{~min})$. Samples were centrifuged $(1500 \times g$, $10 \mathrm{~min}$ ) to separate the aqueous and organic phases at room temperature. The organic phase containing the lipid was removed and transferred to a new glass tube and evaporated under a stream of nitrogen. The lipid extract was reconstituted in $200 \mu \mathrm{l}$ of dichloromethane and lipids were then separated by thin layer chromatography (TLC). The lipid extracts were spotted onto silica gel plates (silica gel $60 \mathrm{G}$, Merck, Germany) and developed in 85:15:2 (v/v) petroleum ether: diethyl ether: acetic acid in paper-lined tanks. The lipids were visualized with $0.1 \%(\mathrm{w} / \mathrm{v})$ $2^{\prime}, 7^{\prime}$-dichlorofluorescein indicator in ethanol (Scharlau, Spain). The phospholipid bands from the samples were scraped off into glass screw-capped tubes and were reacted with $5 \% \mathrm{H}_{2} \mathrm{SO}_{4}$ in $100 \%$ methanol $\left(3 \mathrm{~h}\right.$ at $\left.80^{\circ} \mathrm{C}\right)$ to form the fatty acid methyl esters (FAMEs). FAME were isolated (100\% petroleum ether) and stored in glass $\left(-20^{\circ} \mathrm{C}\right)$. Purified FAME were isolated and identified using an Agilent Technologies 7890A GC System (Agilent Technologies, Santa Clara, CA, USA) equipped with an Omegawax 250 capillary column $(30 \mathrm{~m} \times 0.25 \mathrm{~mm}$ internal diameter, $0.25 \mu \mathrm{m}$ film thickness, Supelco, Bellefonte, PA, USA), a flame ionization detector (FID), an Agilent Technologies 7693 auto sampler, and a split injection system (split ratio 50:1). The injection volume was $1 \mu \mathrm{l}$, the injector and detector temperature were 300 and $270^{\circ} \mathrm{C}$, respectively. The temperature program was $50-190$ at $20^{\circ} \mathrm{C} \mathrm{min}^{-1}$, then from 190 to 250 at $4^{\circ} \mathrm{C} \mathrm{min}^{-1}$, and held at $250^{\circ} \mathrm{C}$ for $8 \mathrm{~min}$. The carrier gas was helium at $1.18 \mathrm{ml} \mathrm{min}^{-1}$, at a constant flow. Each of the fatty acids was identified relative to known external standards (a series of mix and individual standards from Sigma-Aldrich, Inc., St. Louis, MO, USA and from Nu-Chek Prep Inc., Elysian, MN, USA). The resulting peaks were then corrected by the theoretical relative FID response factors (59) and quantified relative to the internal standard.

\section{INFARCT VOLUME ANALYSIS AND AREA OF DAMAGE}

Brains were cut ( $2 \mathrm{~mm}$ coronal sections) using an acrylic rat brain matrix. Tissue was processed using a closed linear Tissue Processing System (Cat No. TPC 15, MEDITE GmbH, Wollenweberstr, Burgdorf, Germany). Tissue was embedded in molten paraffin wax (Cat No. Leica EG1150 H, Leica-microsystems, Ernst-LeitzStraße, Wetzlar, Germany), and stored at room temperature. Tissue was cut at room temperature $(7 \mu \mathrm{m})$ using a rotary microtome (Cat No. Leica 2040, Leica-microsystems, Ernst-Leitz-Straße, Wetzlar, Germany) suspended at $40^{\circ} \mathrm{C}$ in a tissue flotation bath and attached to silane coated slides (Cat No. CS2460100MK, Microglass, Grale Scientific, Melbourne, VIC, Australia). Tissue slides were dried at $49^{\circ} \mathrm{C}$, incubated at $32^{\circ} \mathrm{C}$ for $24 \mathrm{~h}$, and stained with Hematoxylin ( 5 g Hematoxylin; Cat No. 340374T, VWR International Pty Ltd., Murarrie, QLD, Australia) and Eosin (10 g Eosin Y; 
Cat No. E-4382, Sigma-Aldrich, St. Louis, MO, USA). Slides were de-waxed in Histosol (Cat No. CP L HISTOSOL 08, HD Scientific, Wetherill Park, NSW, Australia), washed in ethanol, rinsed in $\mathrm{dH}_{2} \mathrm{O}$, dehydrated in ethanol, followed by two Histosol washes. Slides were rehydrated in ethanol rinsed in $\mathrm{dH}_{2} \mathrm{O}$ and stained with filtered Harris Hematoxylin. Slides were rinsed in $\mathrm{dH}_{2} \mathrm{O}$, stained in filtered Eosin $\mathrm{Y}$, washed in $\mathrm{dH}_{2} \mathrm{O}$, and dehydrated in ethanol. This was followed histosol washes and cover slipping (DPX, Cat No. 1019790500, Merck KGaA, Darmstadt, Germany). Stained tissue was examined and using bright field microscopy (Nikon Eclipse 80i, Nikon Instruments Europe) with a Nikon DIGITAL SIGHT DS-U1 camera. Photographs were stored as JPEG Image files. Areas of tissue damage were analyzed using Stereo Investigator Version 6 software.

\section{DATA ANALYSIS}

The present study uses both parametric and non-parametric data analysis techniques as appropriate. This study consists of four independent groups [ $2 \times 2(n$-3-LC-PUFA MCAo; Basal MCAo; n-3-LC-PUFA sham; Basal Sham)] and has both single time point and repeated measures outcomes. Where data met the assumption of normality, appropriate ANOVAs, as described below are used. All measures of longer-term behavioral outcomes however did not meet the assumption of normality and were unable to be transformed (except spatial displacement recognition) and thus non-parametric data analyses techniques have been used. It is important to note however, that IBM SPSS Statistics does not offer a non-parametric equivalent to the mixed design ANOVA (the appropriate parametric analysis technique to analyze the longerterm behavioral outcome data). The non-parametric Friedman's ANOVA allows a comparison of two or more related groups, but is not appropriate for the current study, where groups are independent. The Kruskal-Wallis is appropriate for the current data, as it allows one to compare differences between two or more independent groups (i.e., $n$-3-LC-PUFA MCAo vs. Basal MCAo/n3-LC-PUFA sham vs. Basal Sham) (60). To determine where group differences exist, Mann-Whitney post hoc tests were used. In order to control for type 1 errors, only the most important/relevant post hoc Mann-Whitney comparisons were made, thus differences between diet groups; within each of the different surgery conditions, at weeks 2, 4, and 6 post-surgery, have not been assessed. We determined that the most important/relevant post hoc MannWhitney comparisons are: (a) differences between MCAo operated and Sham operated rats and (b) differences between $n$-3-LC-PUFA and basal diet fed rats, at weeks 2,4 , and 6 post-surgery, and thus these group differences have been assessed.

For single time point outcome measures, where the assumptions of normality were met [infarct volume and total fatty acid levels (micrograms) in brain phospholipids] ANOVAs were conducted. For outcome variables measured at multiple time points [body weight, food, and water consumption (grams), acute strokerelated motor impairment and spatial displacement recognition] mixed design ANOVAs were conducted (effect of diet condition within surgery condition measured at multiple time points). LSD post hoc test with a Bonferroni correction were used. Normality of data from behavioral tests was assessed using Q-Q plots and histograms. Outliers were screened for using box plots and no data was deleted, the assumptions of homogeneity was checked using Levene's Test of Equality of Variance, and sphericity was checked using Mauchly's Test of Sphericity. A square root transformation was conducted on spatial displacement recognition data to achieve a normal distribution. Spearman correlations were used to detect correlations between emergence behavior and infarct damage. Spearman correlations were also conducted between both the number of emergences from the hide box into the open field and the duration of time spend moving around the open-field arena, and the percentage of emergence time spent in the center of the open-field arena. Independent sample $t$ tests were used to compare mean differences in animal weight and the number of animals that died from hemorrhage following the reperfusion component of the surgery, as reported below, between diet groups at time of surgery.

\section{RESULTS \\ USING PARAMETRIC DATA ANALYSIS TECHNIOUES Increased risk of reperfusion related hemorrhage following reperfusion among n-3-LC-PUFA supplemented animals}

An unexpected finding of the present research that has not previously been reported was that $39 \%(N=11)$ of all the $n$-3-LCPUFA diet acclimated animals that underwent MCAo surgery experienced subarachnoid hemorrhagic bleeding following the reperfusion component of the surgery, as illustrated in Figure 1. Upon unblinding of groups, we found that this surgical complication was only seen in the $n$-3-LC-PUFA diet acclimated animals and did not occur in any of the basal diet fed rats. We did note any intracerebral bleeding in animals in either of the diet groups. Independent sample $t$ tests indicate that the difference in the rate of reperfusion related bleeding between diet groups was significant, $t(17)=3.29, p<0.01$. These animals were obviously excluded from the final cohort numbers. A further 16 rats who did not experience hemorrhagic bleeding were culled after surgery, due to MCAo symptoms too large for the animal to survive. All these rats were replaced and thus the total number of animals used in the present study was 75 ( $n=29 n$-3-LC-PUFA MCAo; $n=22$ Basal MCAo; $n=12 n$-3-LC-PUFA sham; $n=12$ Basal Sham). Unfortunately, as the death of the $n$-3-LC-PUFA fed animals following the reperfusion component of the surgery was unexpected we were unable to prepare the tissue for further experimental analysis.

\section{ANIMAL WEIGHT FROM TIME OF SURGERY UNTIL SACRIFICE}

Surviving animal $(N=48)$ mean bodyweight was $337(\mathrm{SD}=36.5)$ grams at time of surgery. There was no main effect for diet condition in mean bodyweight at time of surgery, $F(1$, $47)=1.14, p=0.29(n$-3-LC-PUFA $M=332, \mathrm{SE}=6.7$, Basal $M=342, \mathrm{SE}=6.4)$. Between surgery conditions, sham operated rats were slightly lighter than MCAo operated animals, $F(1$, $47)=14.24, p<0.01$ (MCAo $M=354, \mathrm{SE}=6.6$, Sham $M=320$, $\mathrm{SE}=6.6)$. There was no interaction between diet and surgery condition on animal body weight at the time of surgery.

\section{FOOD AND WATER CONSUMPTION FROM TIME OF SURGERY UNTIL SACRIFICE}

Rats did not differ in food and water consumption at the time of surgery (see Figures 2 and 3). On average at the time of surgery, 


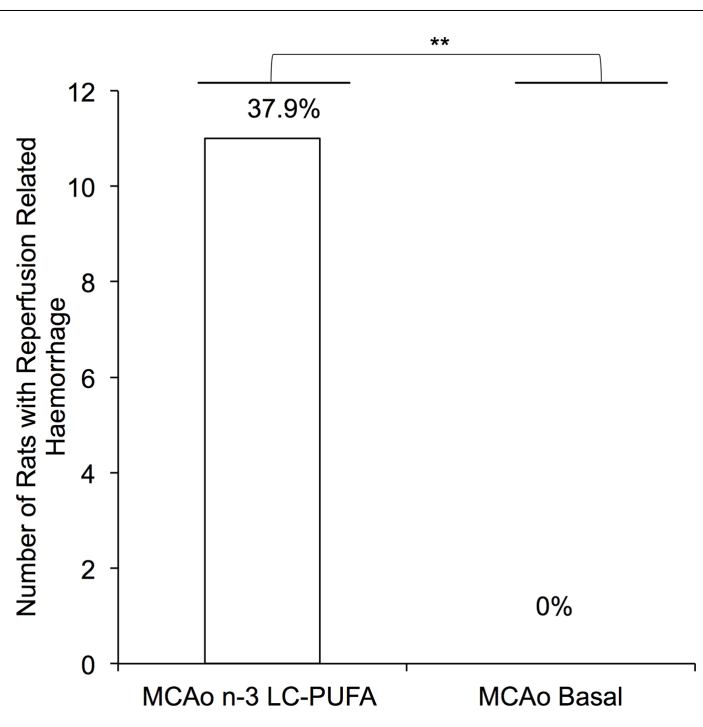

FIGURE 1 | Number of MCAo operated rats that experienced reperfusion related hemorrhage, between diet conditions. MCAO, middle cerebral artery occlusion surgery condition; Basal, basal diet fed rats; $n$-3-LC-PUFA, polyunsaturated fatty acid supplemented rats; $n=11$ $n$-3-LC-PUFA MCAo; $n=0$ basal MCAo.

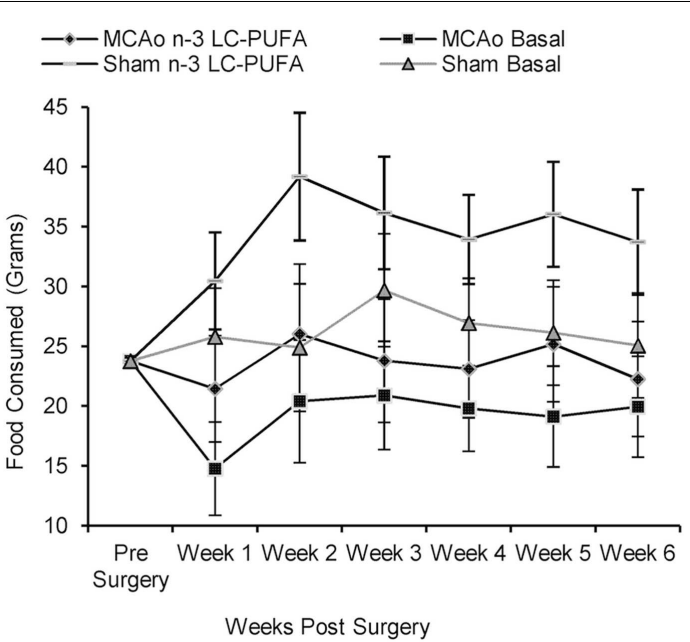

FIGURE 2 | Mean food consumption (shown with confidence intervals), between stroke and diet conditions from week 1 until week 6 post-surgery. MCAo, middle cerebral artery occlusion surgery condition; Sham, Sham surgery condition; Basal, basal diet fed rats; n-3-LC-PUFA, polyunsaturated fatty acid supplemented rats; week 1 , week one post-surgery; week 2, week two post-surgery; week 3, week three post-surgery; week 4, week four post-surgery; week 5, week five post-surgery; week 6 , week six post-surgery. $n=11$-3-LC-PUFA MCAo; $n=13$ Basal MCAo; $n=12$-3-LC-PUFA sham; $n=12$ Basal Sham.

sham operated $n$-3-LC-PUFA diet fed animals were consuming $\sim 206 \mathrm{mg}$ of EPA, and $909 \mathrm{mg}$ of DHA per day, per kilogram of total body weight. MCAo operated $n$-3-LC-PUFA diet fed rats were consuming $181 \mathrm{mg}$ of EPA and $800 \mathrm{mg}$ of DHA per day, per kilogram of total body weight.

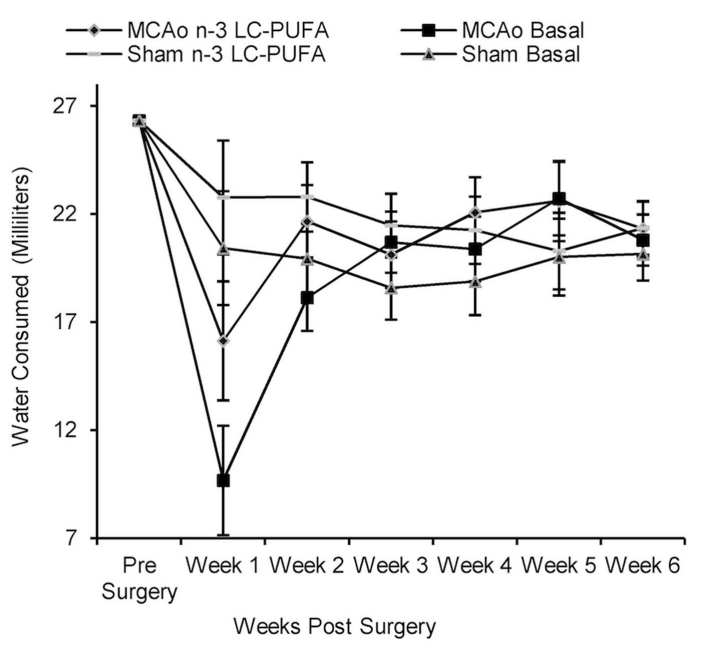

FIGURE 3 | Mean water consumption (shown with confidence intervals), between surgery and diet conditions from week 1 until week 6 post-surgery. Note the large drop in water consumption immediately after surgery and the rapid recovery in drinking behavior, by week 2 post-surgery, and by the time that ischemia associated motor impairments were no longer obvious. MCAo, middle cerebral artery occlusion surgery condition; Sham, Sham surgery condition; Basal, basal diet fed rats; -3-LC-PUFA, polyunsaturated fatty acid supplemented rats; week 1, week one post-surgery; week 2, week two post-surgery; week 3 , week three post-surgery; week 4, week four post-surgery; week 5, week five post-surgery; week 6 , week six post-surgery. $n=11 n$-3-LC-PUFA MCAo; $n=13$ Basal MCAo; $n=12 n$-3-LC-PUFA sham; $n=12$ Basal Sham.

All animals increased in bodyweight from week 1 until week 6 post-surgery, $F(59,205)=30.43, p<0.01$. Food, $F(5,215)=5.79$, $p<0.01$ and water, $F(5,220)=13.10, p<0.01$ consumption increased between week 1 and week 6 post-surgery. A main effect of surgery condition was seen and as MCAo operated animals consumed less food from week 1 until week 6 post-surgery, $F(1,43)=25.46, p<0.01$ and drank less water, $F(1,44)=4.40$, $p<0.05$, than sham operated animals. A main effect of diet condition was also seen over the same period of time, as $n$-3-LC-PUFA supplemented animals consumed more food, $F(1,43)=12.47$, $p<0.01$, and water, $F(1,44)=18.06, p<0.01$ than basal diet fed rats. No interaction effects were seen.

During the 6-weeks post-surgery, sham operated $n$-3-LC-PUFA diet fed animals consumed an average of $272 \mathrm{mg}$ of EPA and $1200 \mathrm{mg}$ of DHA daily, per kilogram of total body weight. On average, MCAo operated n-3-LC-PUFA diet fed animals consumed $189 \mathrm{mg}$ of EPA and $833 \mathrm{mg}$ of DHA daily, per kilogram of total body weight. Figures 2 and 3 show the mean food consumption in grams and mean water consumption in milliliters respectively, between stroke and diet conditions, between week 1 and 6 post-surgery.

\section{FATTY ACID ANALYSIS}

Fatty acid levels are reported as percentage of total FAME. There were no main effects of surgery condition on fatty acid levels. ANOVA showed a main effect for diet condition of fatty acid levels, as $n$-3-LC-PUFA fed animals showed less $n-6$ in whole brain tissue 
than animals fed the basal diet, evidenced by less arachidonic acid $(\mathrm{AA} ; 20: 4, n-6), F(1,23)=8.01, p<0.05$, linoleic acid (LA; 18:2, $n-6), F(1,23)=37.41, p<0.01$ and palmitic acid $(16: 0)$ in brain phospholipids, $F(1,23)=5.51, p<0.05$. A trend for higher levels of eicosatrienoic acid (ETA; 22:3, $n$-3), $F(1,23)=3.85, p=0.06$, among $n$-3-LC-PUFA fed rats than basal fed rats was seen. No main significant main effect of diet was seen in the amount of DHA $(22: 6, n-3), F(1,23)=0.30, p>0.05$, or EPA $(20: 5, n-3)$, $F(1,23)=0.72, p>0.05$. There were no significant interaction effects. Figure 4 illustrates differences in the mean fatty acid levels in the brain phospholipids between diet and surgery conditions.

\section{INFARCT VOLUME ANALYSIS AND AREA OF DAMAGE}

Mean volume (cubic millimeter) of damaged tissue between stroke and diet conditions at week 6 post-surgery and an outline of infarct area 6-weeks after MCAo, is illustrated in Figure 5. MCAo affected animals showed a greater volume (cubic millimeter) of damaged tissue, $F(3,20)=21.82, p<0.01(M=78.72, \mathrm{SE}=16.12)$ when compared to sham operated animals that did not show any infarct damage $(M=0.0, \mathrm{SE}=0.0)$. No main effect on infarct volume was found for diet condition, $F(3,20)=0.14, p>0.05$ ( $n$-3-LC-PUFA, $M=36.23, \mathrm{SE}=16.15$; basal, $M=42.50, \mathrm{SE}=16.76)$. No significant interaction effects were seen. In MCAo operated animals,

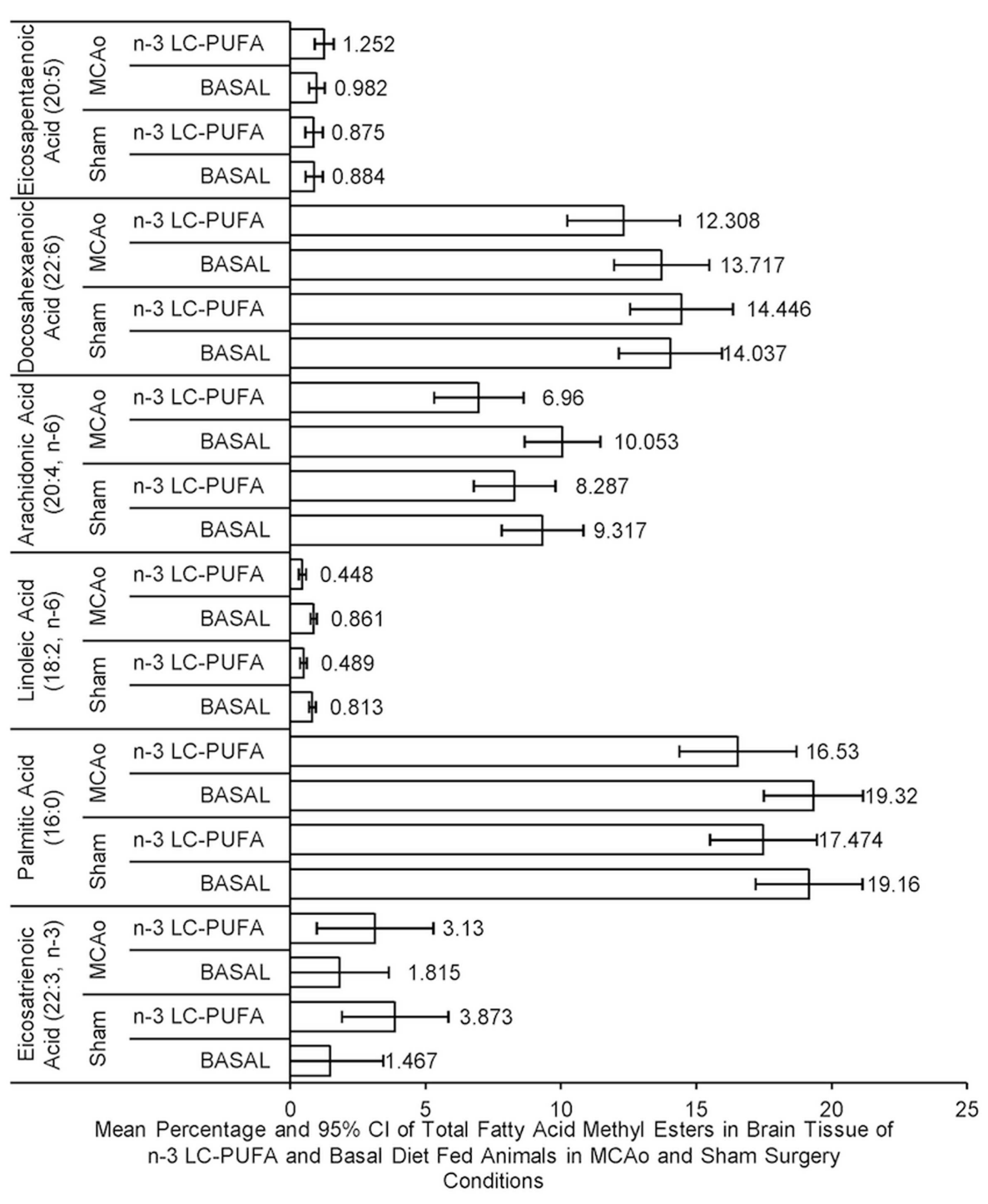

FIGURE 4 | Mean percentage and confidence intervals of whole brain phospholipid fatty acids in fatty acid methyl esters between diet and surgery conditions. Note that although no difference between dietary conditions is seen in the level of eicosapentaenoic acid (20:5) or docosahexaenoic acid (22:6), the levels of fatty acids (palmitic acid [16:0], arachidonic acid [20:4], and linoleic acid [18.2]) were higher in basal diet fed animals, compared to n-3-LC-PUFA fed animals, in whole brain tissue. By comparison, $n$-3-LC-PUFA fed animals are shown to express more omega-3 derived fatty acids [eicosatrienoic acid (22:3)] than basal diet fed animals. No differences are seen in fatty acid methyl esters between surgery groups. -20:5 n-3, eicosapentaenoic acid; 22:6 n-3, docosahexaenoic acid; 20:4 n-6, arachidonic acid; 18:2 n-6, linoleic acid; 16:0, palmitic acid; 22:3 n-3, eicosatrienoic acid. MCAo, middle cerebral artery occlusion surgery condition; Sham, Sham surgery condition; Basal, basal diet condition; $n$-3-LC-PUFA, $n$-3 L-C-PUFA enriched diet condition. * Denotes statistically significant at $p=0.05,{ }^{*}$ denotes statistically significant at $p=0.01 . n=11$ $n$-3-LC-PUFA MCAo; $n=13$ Basal MCAo; $n=12 n$-3-LC-PUFA sham; $n=12$ Basal Sham. 


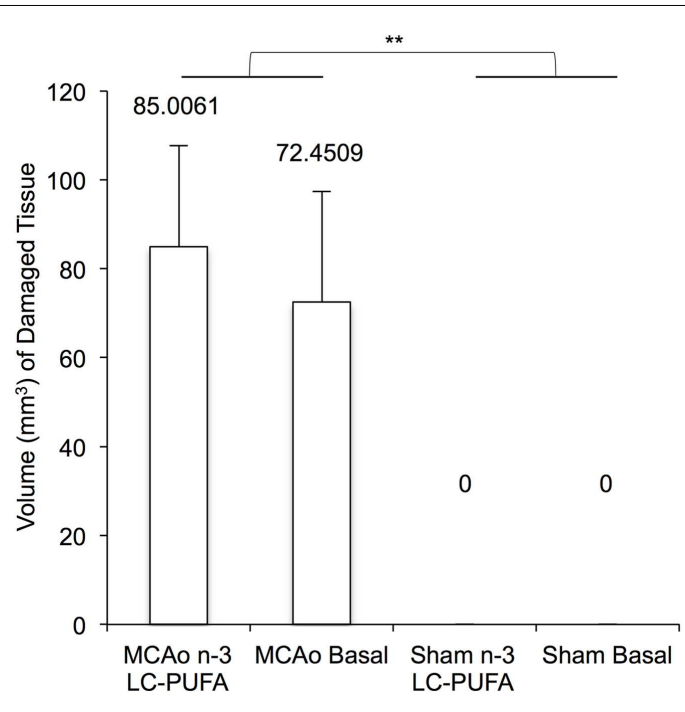

FIGURE 5 | Mean volume (cubic millimeter) of damaged tissue (shown with standard error), between stroke and diet conditions at week 6 post-surgery and outline of infarct area 6-weeks after middle cerebral artery occlusion. Variability was seen in infarct size and animals $(n=5)$ with smaller infarcts generally showed atrophy in the area 1 outline, animals with larger infarcts $(n=5)$ showed atrophy in the both area 1 and 2. (1) area of atrophy in animals with smaller infarcts; (2) area of atrophy additional to area

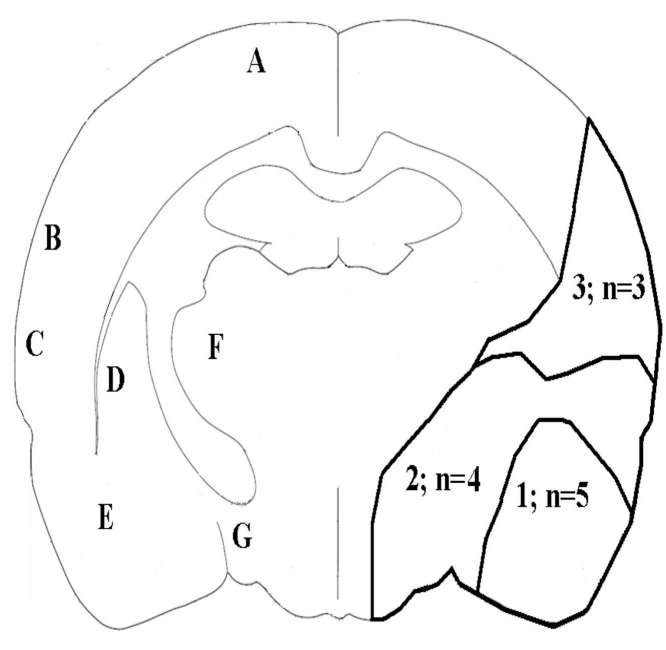

A in animals with larger infarcts; A, motor areas $M 1$ and $M 2 ; B$, somatosensory cortex; C, auditory cortex; D, caudate putamen; E, amygdala region; $F$, ventral posterolateral thalamic nucleus/ventral posteromedial thalamic nucleus; $\mathrm{G}$, lateral hypothalamic area. ${ }^{*}$ Denotes statistically significant at $p=0.05,{ }^{*}$ denotes statistically significant at $p=0.01 . n=11$ $n$-3-LC-PUFA MCAo; $n=13$ Basal MCAo; $n=12 n$-3-LC-PUFA sham; $n=12$ Basal Sham. right hemisphere infarct was seen in cortical and subcortical tissue. Variability was seen in infarct size. The area labeled A in Figure 5 outlines the infarct region typically seen in animals with smaller infarcts $[n=5(n$-3-LC-PUFA diet $=2)]$. Both the areas labeled $\mathrm{A}$ and $\mathrm{B}$ outline the infarct region seen in animals with medium infarcts $[n=4(n$-3-LC-PUFA diet $=1)]$. The areas outlined A, $\mathrm{B}$, and $\mathrm{C}$ outlines the infarct region seen in animals with larger infarcts $[n=3(n-3$-LC-PUFA diet $=3)]$.

\section{ACUTE STROKE-RELATED MOTOR IMPAIRMENT MEASURES}

Main effects for surgery condition were found for all motor impairment measures, with MCAo operated animals showing greater impairment, forelimb flexion, $F(1,36)=19.32, p<0.01$, torso twisting, $F(1,35)=40.29, p<0.01$, lateral push, $F(1,36)=36.34$, $p<0.01$, circling, $F(1,35)=52.52, p<0.01$ and motor ability, $F(1$, $36)=23.04, p<0.01$. A significant main effect of diet condition was seen for lateral push, $F(1,36)=4.34, p<0.05$.

Interaction effects between diet and surgery condition were seen for lateral push, $F(1,36)=4.34, p<0.05$, and motor ability $F(1,36)=5.22, p<0.05$, with $n$-3-LC-PUFA MCAo operated rats showing a smaller impairment than basal fed rats (lateral push: MCAo Basal $M=0.20$, MCAo $n$-3-LC-PUFA $M=0.10$; motor ability: MCAo Basal $M=0.40$, MCAo $n$-3-LC-PUFA $M=0.20$ ) and sham exposed rats showing minimal impairment, irrespective of diet condition (lateral push: Sham Basal $M=0.0$, Sham $n$-3-LC-PUFA $M=0.0$; motor ability: Sham Basal $M=0.0$, Sham $n$-3-LC-PUFA $M=0.05$ ).

Repeated measures ANOVA showed a decrease in motor impairment from day 1 , until day 5 post-surgery. A statistically significant main effect for days after surgery was seen in the torso twisting test, $F(3,118)=3.23, p<0.05$, lateral push test,
$F(4,144)=3.01, p<0.05$, circling, $F(4,140)=4.78, p<0.01$, and motor ability observations, $F(4,144)=5.65, p<0.01$.

\section{LONGER-TERM ISCHEMIA ASSOCIATED BEHAVIORAL DISORDERS Spatial displacement recognition - classically considered a test for} spatial memory deficits

No main effects were found for surgery condition, $F(1,44)=0.14$, $p=0.71$, or diet condition, $F(1,44)=0.09, p=0.77$ at any testing time point post-surgery. There were no interaction effects. All animals were found to explore the displaced object equally.

\section{NON-PARAMETRIC DATA ANALYSIS TECHNIQUES Free exploration test - locomotor hyperactivity}

Measures of locomotor hyperactivity were significantly correlated with each other $(r h o=0.82, p<0.00)$, indicating that these two outcomes are likely reflecting the same construct. Spearman correlation showed a positive correlation between total infarct volume and emergence number at weeks $2($ rho $=0.47, p<0.05)$ and 6 $($ rho $=0.44, p<0.05)$ and a trend at week $4($ rho $=0.39, p=0.06)$.

Kruskal-Wallis non-parametric analysis showed that diet and surgery groups differed in the number of full body emergences from the hide box into the open field, at weeks $4[H(3)=7.81$, $p=0.05]$ and $6[H(3)=10.34, p<0.05]$, and in the total duration spent emerged and moving in the open field at week 6 $[H(3)=10.00, p<0.05]$. Post hoc Mann-Whitney tests show that MCAo affected animals made more emergences from the hide box into the open field than sham affected animals at weeks 4, $U=179.5, z=-2.39, p<0.05$ (MCAo, $\operatorname{mdn}=1, \mathrm{IQR}=2.75$; Sham, $\operatorname{mdn}=0 ; \mathrm{IQR}=1$ ) and $6, U=155, z=-2.87, p<0.01$ $(\mathrm{MCAo}, \mathrm{mdn}=2, \mathrm{IQR}=3.5$; Sham, $\mathrm{mdn}=0 ; \mathrm{IQR}=1.75)$. Emergence duration similarly differed between surgery groups at week 
$6, U=1.72, z=-2.48, p<0.05$ with MCAo animals $(\operatorname{mdn}=145$; $\mathrm{IQR}=177)$ spending more seconds emerged than sham $(\mathrm{mdn}=8$; $\mathrm{IQR}=116)$ affected animals, indicative of more stroke-related locomotor hyperactivity. A comparison of diet conditions showed that $n$-3-LC-PUFA animals $(\operatorname{mdn}=15$; IQR $=145)$ spent fewer seconds out in the open-field area than basal fed rats $(\mathrm{mdn}=95$; $\mathrm{IQR}=189$ ) at week 6 post-surgery, $U=195, z=-1.99, p<0.05$, suggesting that $n$-3-LC-PUFA supplementation reduced locomotor hyperactivity by 6 weeks post-surgery. Figures 6 and 7 depict box plots showing significant post hoc differences between groups.

\section{FREE EXPLORATION TEST - CLASSICALLY A TEST OF ANXIETY-LIKE BEHAVIOR}

The above outlined measures of locomotor activity were both found to be negatively correlated with the percentage of total emergence time spent in the center of the open-field arena [emergence number $(\mathrm{rho}=-0.35, p<0.01)$ and duration of time spent moving in the open-field arena (rho $=-0.45, p<0.01)]$, indicating that they are unlikely to reflect anxiety-like behavior in operated animals.

Non-parametric Kruskal-Wallis test indicated that surgery and diet groups differed in the percentage of total emergence time spent in the center of the open-field arena at 4 weeks post-surgery, as compared to side wall of the arena, $H(3)=7.79, p<0.05$. At 6 weeks post-surgery, an effect for a difference in the percentage of total emergence time spent in the center of the open field arena

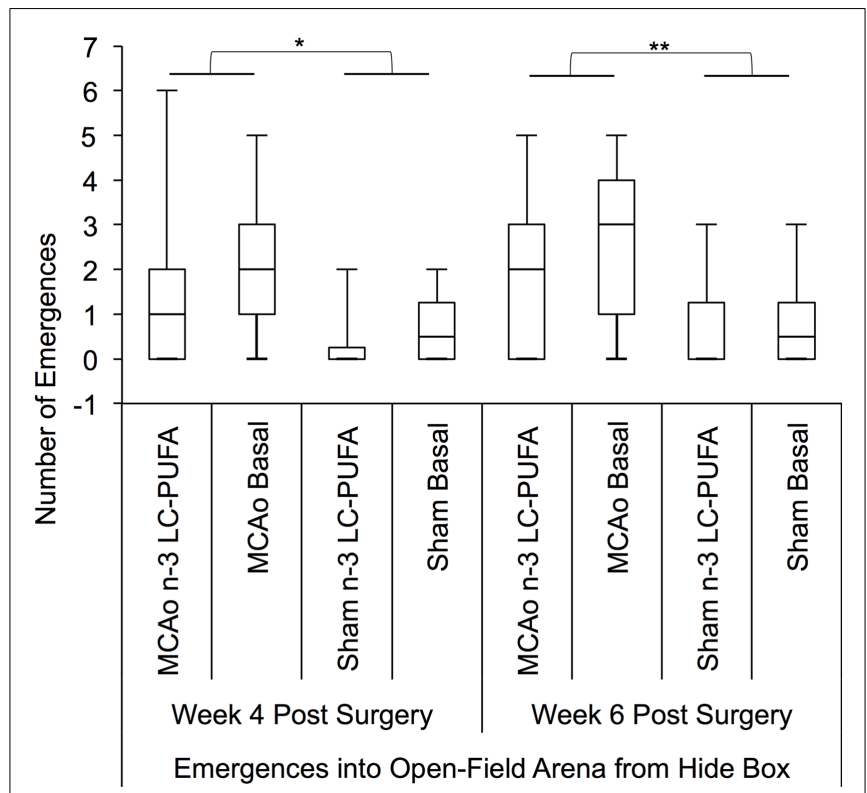

FIGURE 6 | Box plots showing significant post hoc differences in number of emergences into open field, between diet and surgery conditions. Visual inspection of this Figure indicates that sham surgery-operated animals were less active than MCAo operated animals and that in each surgery condition, at each time point, the n-3-LC-PUFA animals emerged from the hide box less often, suggesting less hyperactivity. MCAo, middle cerebral artery occlusion surgery condition; Sham, Sham surgery condition; Basal, basal diet fed rats; $n$-3-LC-PUFA, polyunsaturated fatty acid supplemented rats. $n=11 n$-3-LC-PUFA MCAo; $n=13$ Basal MCAo; $n=12 n$-3-LC-PUFA sham; $n=12$ Basal Sham. approached significance, $H(3)=7.25, p=0.06$. The appropriate post hoc Mann-Whitney test indicated that rats supplemented with $n$-3-LC-PUFA spent significantly a greater percentage of total emergence time in the center of the arena at week $4, U=16.2 .0$, $z=-2.72, p<0.01(n-3$-LC-PUFA, $\operatorname{mdn}=66, \mathrm{IQR}=80$; Basal, $\mathrm{mdn}=0 ; \mathrm{IQR}=51$ ), and week $6, U=161.5, z=-2.65, p<0.01$ $(n-3$-LC-PUFA, $\mathrm{mdn}=70, \mathrm{IQR}=40 ;$ Basal, $\mathrm{mdn}=40 ; \mathrm{IQR}=56)$, compared to basal diet fed rats. Post hoc tests showed no differences between surgery conditions. Figure 8 depicts box plots showing significant post hoc differences between groups.

\section{NOVEL OBJECT EXPLORATION - CLASSICALLY CONSIDERED A TEST OF APPROACH AVOIDANCE BEHAVIORS}

Approach-avoidance conflict was studied using the novel object exploration test. Box plots are presented in Figure 9. Surgery and diet groups differed in novel object exploration time at 4 weeks, $H(3)=9.00, p<0.01$, and 6 weeks post-surgery, $H(3)=12.50$, $p<0.01$.

Post hoc comparisons between surgery conditions showed MCAo affected animals explored the novel object less (in seconds) than sham operated animals at week 4 post-surgery, $U=175, z=-2.32, p<0.05$ (MCAo, $\operatorname{mdn}=6, \mathrm{IQR}=17$; Sham, $\mathrm{mdn}=17 ; \mathrm{IQR}=42)$. Animals did not demonstrate any MACo

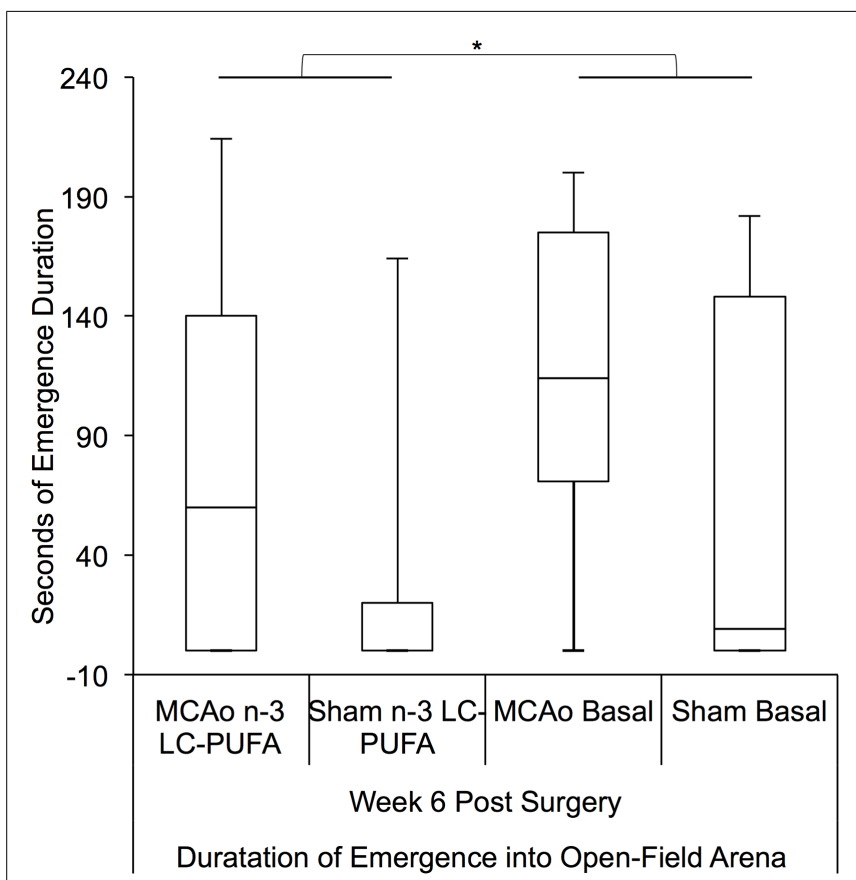

FIGURE 7 | Box plots showing significant post hoc differences in emergence duration between diet and surgery conditions at 6 weeks post-surgery. Visual inspection of this Figure indicates that sham surgery-operated animals spent less time moving around in the open-field arena compared to MCAo operated animals. Furthermore, in each surgery condition, n-3-LC-PUFA diet fed animals spent less time moving around the open-field arena than do basal diet fed animals. MCAo, middle cerebral artery occlusion surgery condition; Sham, Sham surgery condition; Basal, basal diet fed rats; $n$-3-LC-PUFA, polyunsaturated fatty acid supplemented rats. $n=11 n$-3-LC-PUFA MCAo; $n=13$ Basal MCAo; $n=12 n$-3-LC-PUFA sham; $n=12$ Basal Sham. 


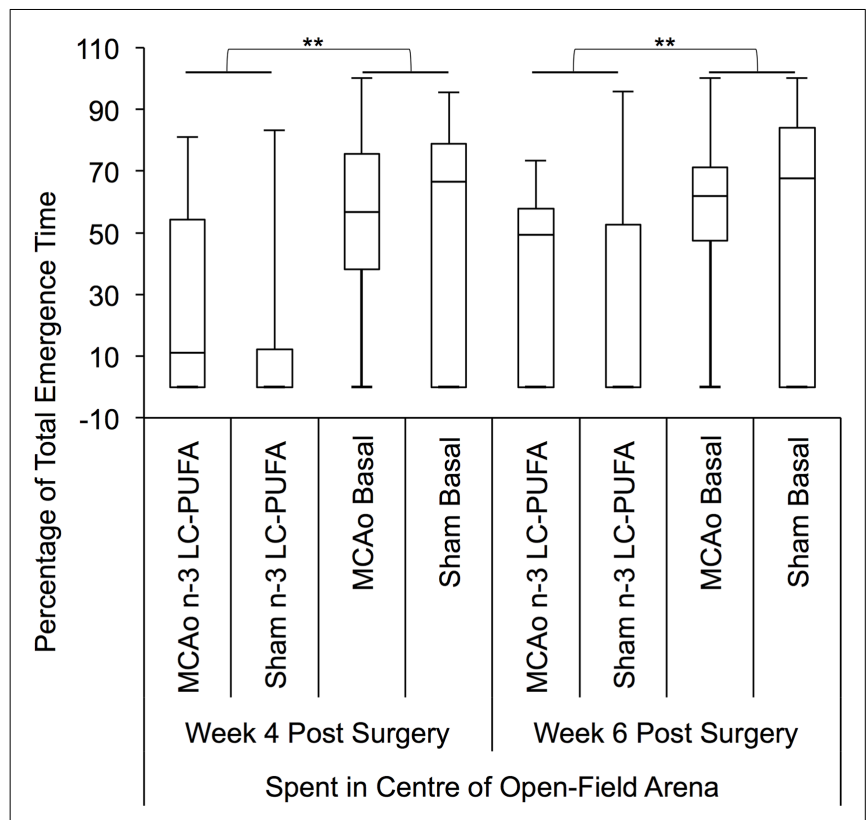

FIGURE 8 | Box plots showing significant post hoc differences in percentage of total emergence time spent in center of open field, compared to the side wall of the open-field arena, between diet and surgery conditions. Visual inspection of this figure indicates that n-3-LC-PUFA diet fed animals spent more time in the center of the arena, than did basal diet fed animals. No effects of surgery condition on percentage of time spent in the center of the arena can be seen. MCAo, middle cerebral artery occlusion surgery condition; Sham, Sham surgery condition; Basal, basal diet fed rats; $n$-3-LC-PUFA, polyunsaturated fatty acid supplemented rats. $n=11 n$-3-LC-PUFA MCAo; $n=13$ Basal MCAo; $n=12$ $n$-3-LC-PUFA sham; $n=12$ Basal Sham.

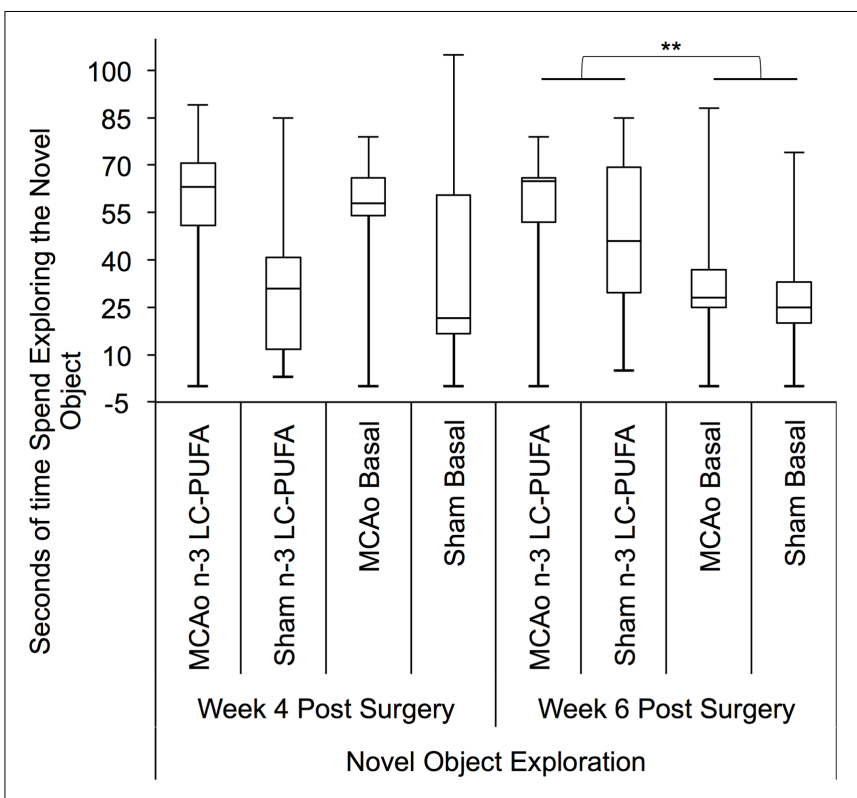

FIGURE 9 | Box plots showing significant post hoc differences in time spent exploring novel object exploration between diet and surgery conditions both at $\mathbf{4}$ and $\mathbf{6}$ weeks post-surgery. Visual inspection of this figure indicates that at both time points sham surgery-operated animals supplemented with $n$-3-LC-PUFA diet spent more time exploring the novel object than sham operated basal diet fed animals. MCAo surgery-operated animals supplemented with n-3-LC-PUFA diet appear to have spent slightly more time exploring the novel object than MCAo operated basal diet fed animals. MCAo, middle cerebral artery occlusion surgery condition; Sham, Sham surgery condition; Basal, basal diet fed rats; $n$-3-LC-PUFA, polyunsaturated fatty acid supplemented rats. $n=11 n$-3-LC-PUFA MCAo; $n=13$ Basal MCAo; $n=12$-3-LC-PUFA sham; $n=12$ Basal Sham. related motor deficits that might have been responsible for changes in exploration behaviors. Post hoc comparison of diet conditions showed that the $n$-3-LC-PUFA supplemented animals in each surgery condition spent more significantly more seconds exploring the novel object than the basal fed animals at week $6, U=144$, $z=-2.95, p<0.01$ ( $n$-3-LC-PUFA, $\mathrm{mdn}=31$, IQR $=23$; Basal, $\mathrm{mdn}=14 ; \mathrm{IQR}=15)$. At weeks 4 , an effect for greater exploration of the novel object by $n$-3-LC-PUFA supplemented animals compared to basal diet fed animals approached significance, $U=198$, $z=-1.85, p=0.06$ ( $n$-3-LC-PUFA, $\mathrm{mdn}=17, \mathrm{IQR}=28$; Basal, $\operatorname{mdn}=5 ; \mathrm{IQR}=18)$.

\section{DISCUSSION}

We aimed to investigate effects of on-going $n$-3-LC-PUFA supplementation on surgery induced sickness behaviors, motor impairment, and anxiety-like and locomotor behaviors. To our knowledge, this is the first rodent study to explore the effects of $n$ 3-LC-PUFA supplementation against persistent anxiety-like and locomotor behaviors post-surgery.

Surprisingly, increased reperfusion related hemorrhagic risk in MCAo $n$-3-LC-PUFA supplemented rats occurred, even after only a short acclimation period ( 1 week prior to surgery). Thus, while $n$-3-LC-PUFA supplementation may reduce affective and behavioral disorders, it also appears to be associated with increased risk of hemorrhagic bleeding. Unfortunately, the death of the $n$-3LC-PUFA fed animals following the reperfusion component of the surgery was unexpected, we were unable to rescue the tissue for further experimental analysis, and thus, this preliminary data should be interpreted with caution.

As far as we are aware, $n$-3-LC-PUFA related hemorrhagic bleeding has not previously been reported in the context of experimental MCAo. Our findings are consistent however with previous rodent studies, using an experimental model of intracerebral hemorrhage. One study demonstrated that $41 \%$ of animals died due to excessive bleeding after experimentally induced intracerebral hemorrhage, when fed a diet supplemented with 1\% EPA/DHA, for a period of 5 weeks prior to surgery. The authors concluded that the increased mortality might be due to DHA and EPA associated increases in oxidative damage (18). Indeed, FFA expression is seen to increase at 7 days after experimentally induced hemorrhagic stroke in rodents, with expression returning to baseline levels at 14 days post-surgery (61). Another study indicated that 2 weeks of supplementation with fish oil (9\% DHA and 12.9\% EPA) prior to intracerebral hemorrhage, is associated with increased cerebral blood flow in the peri-infarct region and contralateral hemisphere, at $6 \mathrm{~h}$ after surgery, in male Sprague-Dawley rats. Animals fed the fish oil diet also showed greater disability in fine motor control, compared to animals fed a sunflower oil enriched diet (rich in 
omega-6). The above-mentioned disabilities were present in spite of no statistically significant difference in infarct size, between animals in different diet groups (62). A second study indicated high omega-6 AA was negatively associated with gastric hemorrhage, and that 7 days of fish oil supplementation decreases AA in liver phosphatidylcholine. Those authors speculated that fish oil may increase gastric bleeding due to modulating the permeability of cell membranes in the gastric mucosa (63) in their inbred rats that were fed a $7.5 \%$ fish oil diet. Given the limited research, we are unable to specify if hooded-Wistar rats differ in bleeding times, rates of platelet aggregation, and responsiveness to dietary EPA/DHA supplementation compared to other rat strains. After subarachnoid hemorrhage, both animal and clinical studies demonstrate that EPA reduces vasospasm, or contraction of smooth muscle cells, in part via inhibition of $\mathrm{TXA}_{2}$, a thromboxane that increases platelet aggregation. Conversely, the $\mathrm{F}_{2}$-isoprostanes, derived from the omega- 6 fatty AA, are associated with increased risk of subarachnoid hemorrhage related vasospasm (64-69).

In Greenland Eskimos, high PUFA consumption has long been associated with increased incidence of hemorrhagic stroke (70, 71). In clinical populations, a small study involving 20 individuals, demonstrated that PUFAs expression is elevated in the cerebral spinal fluid (CSF) of individuals who experienced hemorrhagic stroke, at 24 until $48 \mathrm{~h}$ after insult, when compared to non-stroke affected individuals (67). A later clinical study by the same authors, involving 25 patients, who experienced either hemorrhagic or ischemic stroke, similarly showed elevated PUFA expression in CSF, within $48 \mathrm{~h}$ following insult, compared to healthy individuals (72). Additionally, PUFA expression was positively correlated with worse outcome at the time of hospital discharge. The authors interpreted these data to indicate the PUFA expression may be a marker of stroke outcome. These authors however found no difference in PUFA expression between individuals who experienced a hemorrhagic stroke compared to those who experienced ischemic stroke (72). Animal studies have also documented elevated PUFA expression after ischemic stroke (73-75) and thus the role of PUFAs in hemorrhagic stroke specifically is still unclear.

Stroke survivors are already considered particularly high risk for hemorrhagic transformation (76-79). Therefore, some authors argue that it is prudent to ensure that patients who are classified as high risk for hemorrhage discontinue $n$-3-LC-PUFA consumption (80). Other authors claim that fish oil consumption is not dangerous in clinical populations (16) and that the empirically supported benefits of PUFA supplementation simply outweigh the yet unproven potential hemorrhagic risks (16). In humans, fish oils do not appear to decrease platelet aggregation (81) or platelet derived growth factor (82). Even when taken in conjunction with other blood thinning agents, such as aspirin and warfarin, fish oil consumption appears to have no significant effect on bleeding (8385). Harris reviewed 19 studies involving individuals taking fish oil after percutaneous transluminal coronary angioplasty, coronary artery bypass grafting, endarterectomy or coronary angiography, and concluded that fish oil supplementation does not increase clinically significant bleeding, and concluded that PUFAs do not appear to affect bleeding (86). It should be noted however, that none of the studies reviewed, investigated the effect of bleeding in relation to cerebral ischemic or hemorrhagic stroke (86). Conversely, an earlier review by Knapp concluded that, while evidence is inconsistent, that polyunsaturated fatty acids do appear to increase template bleeding time in human populations (87). Additionally, a number of clinical studies that have investigated the effects of fatty acids after subarachnoid hemorrhagic stroke, suggest that the omega- 3 fatty acid EPA inhibits vasoconstriction, while the omega- 6 AA, contributes to vasospasm. Thus, in the case of subarachnoid hemorrhagic, fatty acids do appear to influence blood flow in clinical populations (64-69).

Research investigating the neuroprotective effect of $n$-3-LCPUFAs after ischemic stroke, typically begin $n$-3-LC-PUFA administration after the surgical procedure $(19,21)$. In the present research, supplementation commencing after surgery was not appropriate, as we were interested in monitoring sickness behavior post-surgery, and changing the diet after surgery was likely to confound eating behaviors. However, given the increased hemorrhagic bleeding seen in the present study, we suggest that prefeeding with $n$-3-LC-PUFA may be dangerous (16, 17, 76-80). Further research is required to clarify the potential risks of $n$-3-LCPUFA supplementation on hemorrhagic bleeding in vulnerable populations $(62,63)$.

Prolonged changes and decreases in eating and drinking behaviors are a feature of sickness behaviors in animals (88). Therefore, it is not surprising that sham animals had higher food and water intake than MCAo affected animals post-surgery. As hypothesized, $n$-3-LC-PUFA supplemented animals similarly consumed more water than basal fed rats post-surgery. Our unpublished data shows non-surgery affected, normally reared, $n$-3-LC-PUFA supplemented rats, do not consume more food and water than basal diet fed rats. Therefore, it is unlikely that $n$-3-LC-PUFA fed animals drink more due to increased salt or dietary change. In the present study increased water consumption among $n$-3-LCPUFA supplemented rats after surgery could reflect better recovery from surgery, as animals rapidly replace surgery associated blood volume loss.

Not surprisingly, MCAo affected animals showed acute motor impairment in the 5-days following surgery. However, as motor impairment scores in the first 5 days following MCAo did not correlate with infarct size as determined at 6 weeks post-surgery, indicating that early motor impairments is more likely to reflect short term MCAo related ischemia and associated edema rather than longer-term tissue atrophy. Thus, the motor impairment tests used in the present study are not appropriate measures of MCAo related cellular damage in rodents.

MCAo affected animals showed increased locomotive behaviors compared to sham operated animals, which is consistent with previous research (89). Previous authors have speculated that MCAo related locomotor deficits might arise from an inability to habituate to unfamiliar environments, possibly related to spatial mapping difficulties induced by hippocampus cell death (27-30). However, the present research does not indicate "habituation" deficits in ischemia-affected animals, as we found no difference between stroke and sham affected animals in the spatial displacement recognition test at 2, 4, and 6 weeks, post-surgery. It is possible that ischemia associated cell proliferation in the hippocampus may have already occurred by the time the first 
spatial displacement recognition test was conducted, at 2 weeks post-surgery, and corrected any spatial mapping disabilities that may have been previously present. Indeed, MCAo associated hippocampal neuronal degeneration is seen to peak between $12 \mathrm{~h}$ and 7 days after surgery, with no further degeneration after this point, in rodents (90). Additionally, neurogenesis in the adult hippocampus is seen to increase eightfold 1 week after focal ischemia, but return to basal levels 2 and 3 weeks post insult (91). After transient ischemia CA1 neurons are seen to completely repopulate by 1 month post infarct (92). After transient ischemia, treatment with growth factor restores memory function in the Morris water maze task, at 49-53 days after surgery, which positively correlates with the effect of the growth factor on the regeneration of new neurons (92).

After global ischemia, this is associated with improved spatial learning and memory functions, as assessed using a water maze (93). Alternatively, Plamondon and Khan (94) suggest that ischemia-affected rodents do not have habituation deficits at all, but rather that the testing periods often employed are not long enough to allow the animal enough time to become familiar with its environment (94).

In the present study, extensive tissue damage in the somatosensory cortex following the MCAo surgery may have contributed to the changes in locomotory behaviors, as pyramidal neurons of the second and third layers of the somatosensory cortex project to the motor cortex $(29,95)$. Additionally, previous research has associated amygdala damage with a decreased anxiety response that has also been associated with increased exploratory activity (96). While extensive damage was seen in the amygdala of MCAo affected animals in the present study (data not shown), the current results do not suggest that MCAo operated animals showed less anxiety-like behaviors in the free exploration test than sham operated animals. Additionally, we found a negative correlation between both the number of emergences from the hide box into the open field, the time spent moving around in the open field and the percentage of emergence time spent in the center of the openfield arena, indicating that the change in locomotion is unlikely to result from a change in anxiety-like behaviors in surgery affected animals.

We found no obvious difference in the exploration time of the novel object between basal diets fed MCAo and sham operated animals. One interpretation is that MCAo surgery does not prevent the beneficial effect of $n$-3-LC-PUFA supplementation on the exploration behavior of a novel object, or that the positive effect of $n$-3-LC-PUFAs on novel object exploration behavior may be independent of MCAo. Our findings are consistent with previous research demonstrating that anti-depressive interventions, such as electroconvulsive treatment, increase novel objects exploration, in the rodent model (97). However, it should be noted that in the present study, post hoc tests showed no difference between MCAo and sham operated animals, in the percentage of emergence time spent in the center of an open-field arena. The finding that MCAo operated animals explored the novel object less than sham operated animals is consistent with previous research indicating that stressful interventions (conditions of unpredictable chronic stress) induces sickness behavior and inhibit novel object exploration (98). Interestingly, genetically knocking-out the depression associated dopamine D4 receptor in mice has also been shown to be associated with less approach/explore behaviors in the novel object exploration test (44).

A limitation of the present research is that we did not investigate serum or vascular EPA and DHA levels. Previously, EPA administration post MCAo has been shown to improve local cerebral blood flow and metabolism in the rat when administered for 4 weeks via gavage (99). Serum and vasculature tissue have been shown to be more readily responsive to dietary EPA/DHA supplementation than brain tissue $(100,101)$. Thus it is possible that the behavioral effects of $n$-3-LC-PUFA dietary supplementation may relate to the effects of PUFA supplementation on cerebral blood flow. The present findings also indicate an increased reperfusion related hemorrhagic risk in MCAo $n$-3-LC-PUFA supplemented rats, after only a short acclimation period. Further research is required to clarify the potential risks of $n$-3-LC-PUFA supplementation on hemorrhagic bleeding in vulnerable populations. In surviving animals, $n$-3-LC-PUFA supplementation appears to reduce surgery associated hyperactive locomotor and affective symptomology.

In summary, we initially aimed to investigate effects of $n$-3-LCPUFA supplementation on surgery induced acute and longer-term sickness behaviors, acute motor impairment and anxiety-like and locomotor behaviors. However, we were surprised to find an increased risk of hemorrhage following the reperfusion component of the surgery, in a number of MCAo n-3-LC-PUFA supplemented rats. While these findings appear novel in the context of experimental MCAo, they are consistent with the effect of $n$-3-LCPUFA supplementation prior to experimental intracerebral hemorrhage and the role of omega-3 fatty acids in reducing vasoconstriction and thus increasing blood flow, after subarachnoid hemorrhage. In the present study, PUFA supplementation was not seen to influence infarct size at 6 weeks after surgery, in animals that did not experience hemorrhagic bleeding. $n$-3-LC-PUFA supplementation did decrease omega-6-fatty-acid expression, reduce sickness behaviors, acute motor impairment, and longer-term locomotor hyperactivity and depression/anxiety-like behavior. Thus, in MCAo affected rats, $n$-3-LC-PUFA supplementation appears to be associated with both beneficial and detrimental effects. The current data should be interpreted with caution as we were unable to prepare the tissue for further experimental analysis, and thus further research is required to better understand the risks of $n$-3-LC-PUFA supplementation in experimental MCAo.

\section{AUTHORS CONTRIBUTIONS}

Authors' contributions were as follows: Michaela C. Pascoe contributed to the design of the project, conducted the research, and wrote the manuscript; David W. Howells contributed to the design of the project and reviewed the manuscript; David P. Crewther contributed to the design of the project and reviewed the manuscript; Nicki Constantinou contributed to data analysis; Leeanne M. Carey contributed to the design of the project and reviewed the manuscript; Sarah S. Rewell contributed with experimental procedures; Giovanni M. Turchini contributed with experimental procedures, data analysis and reviewed the manuscript; Gunveen Kaur contributed with experimental procedures, Sheila G. Crewther contributed to the design of the project and writing and revision of the manuscript. 


\section{ACKNOWLEDGMENTS}

Special thanks to Associate Professor Trevor Norman of the Department of Psychiatry, University of Melbourne, Austin Hospital, Heidelberg, VIC, Australia for the provision of equipment required for behavioral testing. Special thanks to Professor Andrew Sinclair of Deakin University Warrnambool, VIC, Australia for the provision of facilities to conduct fatty acid analysis. No sources or grants contributed to the completion of this research.

\section{REFERENCES}

1. Mackay J, Mensah G. The Atlas of Heart Disease and Stroke. Geneva: World Health Organization (2004). 112 p.

2. Burvill PW, Johnson GA, Jamrozik KD, Anderson CS, Stewart-Wynne EG, Chakera TM. Anxiety disorders after stroke: results from the Perth Community Stroke Study. Br J Psychiatry (1995) 166(3):328-32. doi:10.1192/bjp.166.3.328

3. Astrom M. Generalized anxiety disorder in stroke patients. A 3-year longitudinal study. Stroke (1996) 27(2):270-5. doi:10.1161/01.STR.27.2.270

4. Linden T, Blomstrand C, Skoog I. Depressive disorders after 20 months in elderly stroke patients: a case-control study. Stroke (2007) 38(6):1860-3. doi:10.1161/STROKEAHA.106.471805

5. Kessler RC, Nelson CB, McGonagle KA, Liu J, Swartz M, Blazer DG. Comorbidity of DSM-III-R major depressive disorder in the general population: results from the US National Comorbidity Survey. Br J Psychiatry Suppl (1996) 168(30):17-30.

6. Hirschfeld RM. The comorbidity of major depression and anxiety disorders: recognition and management in primary care. Prim Care Companion J Clin Psychiatry (2001) 3(6):244-54. doi:10.4088/PCC.v03n0609

7. Pandharipande P, Cotton BA, Shintani A, Thompson J, Pun BT, Morris JA Jr., et al. Prevalence and risk factors for development of delirium in surgical and trauma intensive care unit patients. J Trauma (2008) 65(1):34-41. doi:10.1097/TA.0b013e31814b2c4d

8. Tully PJ, Baker RA, Winefield HR, Turnbull DA. Depression, anxiety disorders and type D personality as risk factors for delirium after cardiac surgery. Aust N Z J Psychiatry (2010) 44(11):1005-11. doi:10.3109/00048674.2010.495053

9. McManus J, Pathansali R, Stewart R, Macdonald A, Jackson S. Delirium poststroke. Age Ageing (2007) 36(6):613-8. doi:10.1093/ageing/afm140

10. Masskulpan P, Riewthong K, Dajpratham P, Kuptniratsaikul V. Anxiety and depressive symptoms after stroke in 9 rehabilitation centers. J Med Assoc Thai (2008) 91(10):1595-602.

11. Dantzer R, O'Connor JC, Freund GG, Johnson RW, Kelley KW. From inflammation to sickness and depression: when the immune system subjugates the brain. Nat Rev Neurosci (2008) 9(1):46-56. doi:10.1038/nrn2297

12. Pascoe MC, Crewther SG, Carey LM, Crewther DP. What you eat is what you are - a role for polyunsaturated fatty acids in neuroinflammation induced depression? Clin Nutr (2011) 30(4):407-15. doi:10.1016/j.clnu.2011.03.013

13. Ross BM. Omega-3 polyunsaturated fatty acids and anxiety disorders. Prostaglandins Leukot Essent Fatty Acids (2009) 81(5-6):309-12. doi:10.1016/j. plefa.2009.10.004

14. Lavialle M, Denis I, Guesnet P, Vancassel S. Involvement of omega-3 fatty acids in emotional responses and hyperactive symptoms. J Nutr Biochem (2010) 21(10):899-905. doi:10.1016/j.jnutbio.2009.12.005

15. Appleton KM, Rogers PJ, Ness AR. Is there a role for $n$-3 long-chain polyunsaturated fatty acids in the regulation of mood and behaviour? A review of the evidence to date from epidemiological studies, clinical studies and intervention trials. Nutr Res Rev (2008) 21(1):13-41. doi:10.1017/S0954422408998620

16. Bays HE. Safety considerations with omega-3 fatty acid therapy. Am J Cardiol (2007) 99(6A):35C-43C. doi:10.1016/j.amjcard.2006.11.020

17. Stone NJ. Fish consumption, fish oil, lipids, and coronary heart disease. Circulation (1996) 94(9):2337-40. doi:10.1161/01.CIR.94.9.2337

18. Park Y, Nam S, Yi HJ, Hong HJ, Lee M. Dietary $n-3$ polyunsaturated fatty acids increase oxidative stress in rats with intracerebral hemorrhagic stroke. Nutr Res (2009) 29(11):812-8. doi:10.1016/j.nutres.2009.10.019

19. Belayev L, Marcheselli VL, Khoutorova L, Rodriguez de Turco EB, Busto R, Ginsberg MD, et al. Docosahexaenoic acid complexed to albumin elicits highgrade ischemic neuroprotection. Stroke (2005) 36(1):118-23. doi:10.1161/01. STR.0000149620.74770.2e
20. Zhang W, Hu X, Yang W, Gao Y, Chen J. Omega-3 polyunsaturated fatty acid supplementation confers long-term neuroprotection against neonatal hypoxic-ischemic brain injury through anti-inflammatory actions. Stroke (2010) 41(10):2341-7. doi:10.1161/STROKEAHA.110.586081

21. Choi-Kwon S, Park KA, Lee HJ, Park MS, Lee JH, Jeon SE, et al. Temporal changes in cerebral antioxidant enzyme activities after ischemia and reperfusion in a rat focal brain ischemia model: effect of dietary fish oil. Brain Res Dev Brain Res (2004) 152(1):11-8. doi:10.1016/j.devbrainres.2004.05.004

22. Petullo D, Masonic K, Lincoln C, Wibberley L, Teliska M, Yao DL. Model development and behavioral assessment of focal cerebral ischemia in rats. Life Sci (1999) 64(13):1099-108. doi:10.1016/S0024-3205(99)00038-7

23. Bederson JB, Pitts LH, Tsuji M, Nishimura MC, Davis RL, Bartkowski H. Rat middle cerebral artery occlusion: evaluation of the model and development of a neurologic examination. Stroke (1986) 17(3):472-6. doi:10.1161/01.STR.17. 3.472

24. Lolic MM, Fiskum G, Rosenthal RE. Neuroprotective effects of acetyl-Lcarnitine after stroke in rats. Ann Emerg Med (1997) 29(6):758-65. doi:10. 1016/S0196-0644(97)70197-5

25. Akpan N, Serrano-Saiz E, Zacharia BE, Otten ML, Ducruet AF, Snipas SJ, et al. Intranasal delivery of caspase-9 inhibitor reduces caspase-6-dependent axon/neuron loss and improves neurological function after stroke. J Neurosci (2011) 31(24):8894-904. doi:10.1523/JNEUROSCI.0698-11.2011

26. Garg P, Duncan RS, Kaja S, Zabaneh A, Chapman KD, Koulen P. Lauroylethanolamide and linoleoylethanolamide improve functional outcome in a rodent model for stroke. Neurosci Lett (2011) 492(3):134-8. doi:10.1016/j. neulet.2011.01.073

27. Chandler MJ, DeLeo J, Carney JM. An unanesthetized-gerbil model of cerebral ischemia-induced behavioral changes. J Pharmacol Methods (1985) 14(2):137-46. doi:10.1016/0160-5402(85)90051-8

28. Wang D, Corbett D. Cerebral ischemia, locomotor activity and spatial mapping. Brain Res (1990) 533(1):78-82. doi:10.1016/0006-8993(90)91798-L

29. Kuroiwa T, Bonnekoh P, Hossmann KA. Therapeutic window of halothane anesthesia for reversal of delayed neuronal injury in gerbils: relationship to postischemic motor hyperactivity. Brain Res (1991) 563(1-2):33-8. doi:10. 1016/0006-8993(91)91511-X

30. Kuroiwa T, Bonnekoh P, Hossmann KA. Locomotor hyperactivity and hippocampal CA1 injury after transient forebrain ischemia of gerbils. Neurosci Lett (1991) 122(2):141-4. doi:10.1016/0304-3940(91)90842-H

31. Liu P, Bilkey DK. The effect of excitotoxic lesions centered on the hippocampus or perirhinal cortex in object recognition and spatial memory tasks. Behav Neurosci (2001) 115(1):94-111. doi:10.1037/0735-7044.115.1.94

32. Mumby DG, Gaskin S, Glenn MJ, Schramek TE, Lehmann H. Hippocampal damage and exploratory preferences in rats: memory for objects, places, and contexts. Learn Mem (2002) 9(2):49-57. doi:10.1101/lm.41302

33. Save E, Poucet B, Foreman N, Buhot MC. Object exploration and reactions to spatial and nonspatial changes in hooded rats following damage to parietal cortex or hippocampal formation. Behav Neurosci (1992) 106(3):447-56. doi:10.1037/0735-7044.106.3.447

34. Callaway JK, Knight MJ, Watkins DJ, Beart PM, Jarrott B. Delayed treatment with AM-36, a novel neuroprotective agent, reduces neuronal damage after endothelin-1-induced middle cerebral artery occlusion in conscious rats. Stroke (1999) 30(12):2704-12; discussion 12. doi:10.1161/01.STR.30.12. 2704

35. Miller AA, Dusting GJ, Roulston CL, Sobey CG. NADPH-oxidase activity is elevated in penumbral and non-ischemic cerebral arteries following stroke. Brain Res (2006) 1111(1):111-6. doi:10.1016/j.brainres.2006.06.082

36. Nieuwenhuijs VB, de Bruijn MT, Schiesser M, Morphett A, Padbury RT, Barritt GJ. Ischemic preconditioning and intermittent ischemia preserve bile flow in a rat model of ischemia/reperfusion injury. Dig Dis Sci (2007) 52(11):3029-37. doi:10.1007/s10620-006-9520-7

37. Venna VR, Deplanque D, Allet C, Belarbi K, Hamdane M, Bordet R. PUFA induce antidepressant-like effects in parallel to structural and molecular changes in the hippocampus. Psychoneuroendocrinology (2009) 34(2):199-211. doi:10.1016/j.psyneuen.2008.08.025

38. National Health and Medical Research Council. Australian Code of Practice for the Care and Use of Animals for Scientific Purposes. 7th ed. Canberra: Australian Government (2004). 84 p.

39. Jones ML, Mark PJ, Mori TA, Keelan JA, Waddell BJ. Maternal dietary omega-3 fatty acid supplementation reduces placental oxidative stress and 
increases fetal and placental growth in the rat. Biol Reprod (2013) 88(2):37. doi:10.1095/biolreprod.112.103754

40. Longa EZ, Weinstein PR, Carlson S, Cummins R. Reversible middle cerebral artery occlusion without craniectomy in rats. Stroke (1989) 20(1):84-91. doi:10.1161/01.STR.20.1.84

41. Spratt NJ, Fernandez J, Chen M, Rewell S, Cox S, van Raay L, et al. Modification of the method of thread manufacture improves stroke induction rate and reduces mortality after thread-occlusion of the middle cerebral artery in young or aged rats. J Neurosci Methods (2006) 155(2):285-90. doi:10.1016/j.jneumeth.2006.01.020

42. Rygula R, Abumaria N, Flugge G, Fuchs E, Ruther E, Havemann-Reinecke U. Anhedonia and motivational deficits in rats: impact of chronic social stress. Behav Brain Res (2005) 162(1):127-34. doi:10.1016/j.bbr.2005.03.009

43. Soffie M, Buhot MC, Poucet B. Cognitive and noncognitive processes involved in selective object exploration: comparison between young adult and old rats. Physiol Behav (1992) 52(5):1029-35. doi:10.1016/0031-9384(92) 90387-H

44. Dulawa SC, Grandy DK, Low MJ, Paulus MP, Geyer MA. Dopamine D4 receptor-knock-out mice exhibit reduced exploration of novel stimuli. J Neurosci (1999) 19(21):9550-6.

45. Belzung C. Hippocampal mossy fibres: implication in novelty reactions or in anxiety behaviours? Behav Brain Res (1992) 51(2):149-55. doi:10.1016/S01664328(05)80208-6

46. Montgomery KC. The relation between fear induced by novel stimulation and exploratory behavior. J Comp Physiol Psychol (1955) 48(4):254-60. doi: $10.1037 / \mathrm{h} 0048596$

47. Dember WN. Response by the rat to environmental change. J Comp Physiol Psychol (1956) 49(1):93-5. doi:10.1037/h0045411

48. Andersen MB, Zimmer J, Sams-Dodd F. Postischemic hyperactivity in the Mongolian gerbil correlates with loss of hippocampal neurons. Behav Neurosci (1997) 111(6):1205-16. doi:10.1037/0735-7044.111.6.1205

49. Kilic E, Kilic U, Bacigaluppi M, Guo Z, Abdallah NB, Wolfer DP, et al. Delayed melatonin administration promotes neuronal survival, neurogenesis and motor recovery, and attenuates hyperactivity and anxiety after mild focal cerebral ischemia in mice. J Pineal Res (2008) 45(2):142-8. doi:10.1111/j.1600079X.2008.00568.x

50. Monteggia LM, Luikart B, Barrot M, Theoloold D, Malkovska I, Nef S, et al. Brain-derived neurotrophic factor conditional knockouts show gender differences in depression-related behaviors. Biol Psychiatry (2007) 61(2):187-97. doi:10.1016/j.biopsych.2006.03.021

51. van Riezen H, Leonard BE. Effects of psychotropic drugs on the behavior and neurochemistry of olfactory bulbectomized rats. In: File SE, editor. Psychopharmacology of Anxiolytics and Antidepressants. New York: Pergamon Press (1991). p. 231-50.

52. Redmond AM, Kelly JP, Leonard BE. Behavioural and neurochemical effects of dizocilpine in the olfactory bulbectomized rat model of depression. Pharmacol Biochem Behav (1997) 58(2):355-9. doi:10.1016/S0091-3057(97)00259-1

53. Garzon J, Delrio J. Hyperactivity induced in rats by long-term isolation further-studies on a new animal-model for the detection of anti-depressants. Eur J Pharmacol (1981) 74(4):287-94. doi:10.1016/0014-2999(81)90047-9

54. Garzon J, Fuentes JA, Delrio J. Anti-depressants selectively antagonize the hyperactivity induced in rats by long-term isolation. Eur J Pharmacol (1979) 59(3-4):293-6. doi:10.1016/0014-2999(79)90293-0

55. Misslin R, Cigrang M. Does neophobia necessarily imply fear or anxiety. Behav Processes (1986) 12(1):45-50. doi:10.1016/0376-6357(86)90069-0

56. Welker WI. Free versus forced exploration of a novel situation by rats. Psychol Rep (1957) 3(1):95-108. doi:10.2466/pr0.1957.3.g.95

57. Bevins RA, Besheer J. Object recognition in rats and mice: a one-trial nonmatching-to-sample learning task to study "recognition memory". Nat Protoc (2006) 1(3):1306-11. doi:10.1038/nprot.2006.205

58. Sinclair AJ, O’Dea K, Dunstan G, Ireland PD, Niall M. Effects on plasma lipids and fatty acid composition of very low fat diets enriched with fish or kangaroo meat. Lipids (1987) 22(7):523-9. doi:10.1007/BF02540369

59. Ackman RG. The gas chromatograph in practical analyses of common and uncommon fatty acids for the 21st century. Anal Chim Acta (2002) 465(1-2):175-92. doi:10.1016/S0003-2670(02)00098-3

60. Field A, Miles J. Discovering Statistics Using SAS. London: SAGE Publications Ltd (2010).
61. Paik M-J, Shin JY, Lee G, Ahn YH. Monitoring of altered free fatty acid metabolic patterns in rat plasma following hemorrhagic stroke. Anal Lett (2011) 44(7):1323-32. doi:10.1080/00032719.2010.512678

62. Clarke J, Herzberg G, Peeling J, Buist R, Corbett D. Dietary supplementation of omega-3 polyunsaturated fatty acids worsens forelimb motor function after intracerebral hemorrhage in rats. Exp Neurol (2005) 191(1):119-27. doi:10.1016/j.expneurol.2004.09.003

63. Huang YS, Watanabe Y, Horrobin DF, Simmons V. Fatty acid changes in liver choline and ethanolamine glycerophospholipids in aspirin-treated rats fed linoleate, gamma-linolenate and fish oil. Clin Physiol Biochem (1989) 7(2):79-86.

64. Badjatia N, Seres D, Carpenter A, Schmidt JM, Lee K, Mayer SA, et al. Free fatty acids and delayed cerebral ischemia after subarachnoid hemorrhage. Stroke (2012) 43(3):691-6. doi:10.1161/STROKEAHA.111.636035

65. Corcoran TB, Mas E, Barden AE, Durand T, Galano JM, Roberts LJ, et al. Are isofurans and neuroprostanes increased after subarachnoid hemorrhage and traumatic brain injury? Antioxid Redox Signal (2011) 15(10):2663-7. doi:10.1089/ars.2011.4125

66. Hsieh YP, Lin CL, Shiue AL, Yin H, Morrow JD, Hsu JC, et al. Correlation of F4neuroprostanes levels in cerebrospinal fluid with outcome of aneurysmal subarachnoid hemorrhage in humans. Free Radic Biol Med (2009) 47(6):814-24. doi:10.1016/j.freeradbiomed.2009.06.026

67. Pilitsis JG, Coplin WM, O’Regan MH, Wellwood JM, Diaz FG, Fairfax MR, et al. Free fatty acids in human cerebrospinal fluid following subarachnoid hemorrhage and their potential role in vasospasm: a preliminary observation. J Neurosurg (2002) 97(2):272-9. doi:10.3171/jns.2002.97.2.0272

68. Shirao S, Fujisawa H, Kudo A, Kurokawa T, Yoneda H, Kunitsugu I, et al. Inhibitory effects of eicosapentaenoic acid on chronic cerebral vasospasm after subarachnoid hemorrhage: possible involvement of a sphingosylphosphorylcholine-rho-kinase pathway. Cerebrovasc Dis (2008) 26(1):30-7. doi:10.1159/000135650

69. Yoneda H, Shirao S, Kurokawa T, Fujisawa H, Kato S, Suzuki M. Does eicosapentaenoic acid (EPA) inhibit cerebral vasospasm in patients after aneurysmal subarachnoid hemorrhage? Acta Neurol Scand (2008) 118(1):54-9. doi:10.1111/j.1600-0404.2007.00983.x

70. Kromann N, Green A. Epidemiological studies in the Upernavik district, Greenland. Incidence of some chronic diseases 1950-1974. Acta Med Scand (1980) 208(5):401-6. doi:10.1111/j.0954-6820.1980.tb01221.x

71. Bjerregaard P, Mulvad G, Pedersen HS. Regional variation in cardiovascular risk factors and ischemic heart disease mortality in Greenland. Int J Circumpolar Health (1998) 57(Suppl 1):302-5.

72. Pilitsis JG, Coplin WM, O'Regan MH, Wellwood JM, Diaz FG, Fairfax MR, et al. Measurement of free fatty acids in cerebrospinal fluid from patients with hemorrhagic and ischemic stroke. Brain Res (2003) 985(2):198-201. doi:10.1016/S0006-8993(03)03044-0

73. Gasparovic C, Rosenberg GA, Wallace JA, Estrada EY, Roberts K, Pastuszyn A, et al. Magnetic resonance lipid signals in rat brain after experimental stroke correlate with neutral lipid accumulation. Neurosci Lett (2001) 301(2):87-90. doi:10.1016/S0304-3940(01)01616-0

74. Nakano S, Kogure K, Abe K, Yae T. Ischemia-induced alterations in lipid metabolism of the gerbil cerebral cortex: I. Changes in free fatty acid liberation. J Neurochem (1990) 54(6):1911-6. doi:10.1111/j.1471-4159.1990. tb04890.x

75. Narita K, Kubota M, Nakane M, Kitahara S, Nakagomi T, Tamura A, et al. Therapeutic time window in the penumbra during permanent focal ischemia in rats: changes of free fatty acids and glycerophospholipids. Neurol Res (2000) 22(4):393-400.

76. Jaillard A, Cornu C, Durieux A, Moulin T, Boutitie F, Lees KR, et al. Hemorrhagic transformation in acute ischemic stroke. The MAST-E study. MAST-E Group. Stroke (1999) 30(7):1326-32. doi:10.1161/01.STR.30.7.1326

77. Motto C, Ciccone A, Aritzu E, Boccardi E, De Grandi C, Piana A, et al. Hemorrhage after an acute ischemic stroke. MAST-I Collaborative Group. Stroke (1999) 30(4):761-4. doi:10.1161/01.STR.30.4.761

78. Motto C, Aritzu E, Boccardi E, De Grandi C, Piana A, Candelise L. Reliability of hemorrhagic transformation diagnosis in acute ischemic stroke. Stroke (1997) 28(2):302-6. doi:10.1161/01.STR.28.2.302

79. Alexandrov AV, Black SE, Ehrlich LE, Caldwell CB, Norris JW. Predictors of hemorrhagic transformation occurring spontaneously and on anticoagulants 
in patients with acute ischemic stroke. Stroke (1997) 28(6):1198-202. doi:10. 1161/01.STR.28.6.1198

80. Berliner AR, Fine DM. There's something fishy about this bleeding. NDT Plus (2011) 4(4):270-2. doi:10.1093/ndtplus/sfr046

81. Balk E, Chung M, Lichtenstein A, Chew P, Kupelnick B, Lawrence A, et al. Effects of omega-3 fatty acids on cardiovascular risk factors and intermediate markers of cardiovascular disease. In: Evidence Report/Technology Assessment No. 93. Rockville, MD: Agency for Healthcare Research and Quality (2004). p. $1-6$.

82. Wallace JM, McCabe AJ, Roche HM, Higgins S, Robson PJ, Gilmore WS, et al. The effect of low-dose fish oil supplementation on serum growth factors in healthy humans. Eur J Clin Nutr (2000) 54(9):690-4. doi:10.1038/sj.ejcn. 1601076

83. Eritsland J, Arnesen H, Gronseth K, Fjeld NB, Abdelnoor M. Effect of dietary supplementation with $n-3$ fatty acids on coronary artery bypass graft patency. Am J Cardiol (1996) 77(1):31-6. doi:10.1016/S0002-9149(97) 89130-8

84. Leaf A, Jorgensen MB, Jacobs AK, Cote G, Schoenfeld DA, Scheer J, et al. Do fish oils prevent restenosis after coronary angioplasty? Circulation (1994) 90(5):2248-57. doi:10.1161/01.CIR.90.5.2248

85. Bender NK, Kraynak MA, Chiquette E, Linn WD, Clark GM, Bussey HI. Effects of marine fish oils on the anticoagulation status of patients receiving chronic warfarin therapy. J Thromb Thrombolysis (1998) 5(3):257-61. doi:10.1023/A:1008852127668

86. Harris WS. Expert opinion: omega- 3 fatty acids and bleeding-cause for concern? Am J Cardiol (2007) 99(6A):44C-6C. doi:10.1016/j.amjcard.2006.11.021

87. Knapp HR. Dietary fatty acids in human thrombosis and hemostasis. Am J Clin Nutr (1997) 65(5 Suppl):1687S-98S.

88. Dantzer R. Cytokine-induced sickness behaviour: a neuroimmune response to activation of innate immunity. Eur J Pharmacol (2004) 500(1-3):399-411. doi:10.1016/j.ejphar.2004.07.040

89. Poignet H, Beaughard M, Lecoin G, Massingham R. Functional, behavioral, and histological changes induced by transient global cerebral ischemia in rats: effects of cinnarizine and flunarizine. J Cereb Blood Flow Metab (1989) 9(5):646-54. doi:10.1038/jcbfm.1989.92

90. Butler TL, Kassed CA, Sanberg PR, Willing AE, Pennypacker KR. Neurodegeneration in the rat hippocampus and striatum after middle cerebral artery occlusion. Brain Res (2002) 929(2):252-60. doi:10.1016/S0006-8993(01) 03371-6

91. Jin K, Minami M, Lan JQ, Mao XO, Batteur S, Simon RP, et al. Neurogenesis in dentate subgranular zone and rostral subventricular zone after focal cerebral ischemia in the rat. Proc Natl Acad Sci U S A (2001) 98(8):4710-5. doi:10.1073/pnas.081011098

92. Nakatomi H, Kuriu T, Okabe S, Yamamoto S, Hatano O, Kawahara N, et al. Regeneration of hippocampal pyramidal neurons after ischemic brain injury by recruitment of endogenous neural progenitors. Cell (2002) 110(4):429-41. doi:10.1016/S0092-8674(02)00862-0

93. Bendel O, Bueters T, von Euler M, Ove Ogren S, Sandin J, von Euler G. Reappearance of hippocampal CAl neurons after ischemia is associated with recovery of learning and memory. J Cereb Blood Flow Metab (2005) 25(12):1586-95. doi:10.1038/sj.jcbfm. 9600153

94. Plamondon H, Khan S. Characterization of anxiety and habituation profile following global ischemia in rats. Physiol Behav (2005) 84(4):543-52. doi:10.1016/j.physbeh.2005.02.001

95. Zhang ZW, Deschenes M. Intracortical axonal projections of lamina VI cells of the primary somatosensory cortex in the rat: a single-cell labeling study. $J$ Neurosci (1997) 17(16):6365-79.

96. LaBar KS, LeDoux JE. Partial disruption of fear conditioning in rats with unilateral amygdala damage: correspondence with unilateral temporal lobectomy in humans. Behav Neurosci (1996) 110(5):991-7. doi:10.1037/0735-7044.110. 5.991

97. Friedman A, Frankel M, Flaumenhaft Y, Merenlender A, Pinhasov A, Feder Y, et al. Programmed acute electrical stimulation of ventral tegmental area alleviates depressive-like behavior. Neuropsychopharmacology (2009) 34(4):1057-66. doi:10.1038/npp.2008.177

98. Rodriguez Echandia EL, Gonzalez AS, Cabrera R, Fracchia LN. A further analysis of behavioral and endocrine effects of unpredictable chronic stress. Physiol Behav (1988) 43(6):789-95. doi:10.1016/0031-9384(88)90378-2

99. Katsumata T, Katayama Y, Obo R, Muramatsu H, Ohtori T, Terashi A. Delayed administration of ethyl eicosapentate improves local cerebral blood flow and metabolism without affecting infarct volumes in the rat focal ischemic model. Eur J Pharmacol (1999) 372(2):167-74. doi:10.1016/S0014-2999(99)00171-5

100. Arterburn LM, Hall EB, Oken H. Distribution, interconversion, and dose response of $n-3$ fatty acids in humans. Am J Clin Nutr (2006) 83(6 Suppl):1467S-76S.

101. Moriguchi T, Loewke J, Garrison M, Catalan JN, Salem N Jr. Reversal of docosahexaenoic acid deficiency in the rat brain, retina, liver, and serum. J Lipid Res (2001) 42(3):419-27.

Conflict of Interest Statement: The authors declare that the research was conducted in the absence of any commercial or financial relationships that could be construed as a potential conflict of interest.

Received: 22 October 2013; accepted: 20 January 2014; published online: 06 February 2014.

Citation: Pascoe MC, Howells DW, Crewther DP, Constantinou N, Carey LM, Rewell SS, Turchini GM, Kaur G and Crewther SG (2014) Fish oil diet associated with acute reperfusion related hemorrhage, and with reduced stroke-related sickness behaviors and motor impairment. Front. Neurol. 5:14. doi: 10.3389/fneur.2014.00014

This article was submitted to Stroke, a section of the journal Frontiers in Neurology. Copyright (c) 2014 Pascoe, Howells, Crewther, Constantinou, Carey, Rewell, Turchini, Kaur and Crewther. This is an open-access article distributed under the terms of the Creative Commons Attribution License (CC BY). The use, distribution or reproduction in other forums is permitted, provided the original author(s) or licensor are credited and that the original publication in this journal is cited, in accordance with accepted academic practice. No use, distribution or reproduction is permitted which does not comply with these terms. 